Fernanda Gaspar do Amaral

\title{
Perfil diário e os mecanismos de produção de melatonina pela glândula pineal de ratos diabéticos por estreptozotocina
}

Tese apresentada ao Instituto de Ciências Biomédicas da Universidade de São Paulo, para obtenção do Título de Doutor em Ciências.

Área de concentração: Fisiologia

Orientador: Prof. Dr. José Cipolla Neto 


\section{RESUMO}

AMARAL, F. G. Perfil diário e os mecanismos de produção de melatonina pela glândula pineal de ratos diabéticos por estreptozotocina. 2009. 181 f. Tese (Doutorado em Fisiologia Humana) - Instituto de Ciências Biomédicas, Universidade de São Paulo, São Paulo, 2009.

A glândula pineal participa da sincronização do metabolismo do organismo às variações do fotoperíodo através da síntese circadiana e noturna de seu hormônio, a melatonina. Essa indolamina tem sua síntese controlada principalmente pela estimulação noradrenérgica e participa da regulação de funções fundamentais para homeostasia, dentre elas a regulação do metabolismo energético. Diabetes mellitus é um distúrbio metabólico complexo que envolve carboidratos, lipídeos e proteínas. É caracterizado por hiperglicemia resultante da perda progressiva da secreção ou da ação da insulina. Trabalhos na literatura mostram o papel da melatonina na regulação da sensibilidade periférica à insulina e na regulação da produção e secreção desse hormônio. Em complementação, dados mostram que a insulina potencia a síntese de melatonina induzida por noradrenalina. Diante da possível existência de uma alça regulatória envolvendo ambos hormônios e da controvérsia existente na literatura sobre a síntese de melatonina em modelos experimentais de diabetes, esse trabalho teve como objetivo avaliar as alterações fisiológicas celulares e moleculares da glândula pineal mediante o quadro de diabetes induzido por STZ $(60 \mathrm{mg} / \mathrm{kg}$, i.p.), 3 e 15 dias pós-indução. Ratos albinos Wistar (250 a $280 \mathrm{~g}$ ), mantidos em biotério com ciclo claro-escuro de $12 \mathrm{~h} / 12 \mathrm{~h}$, foram utilizados em todos os procedimentos experimentais que envolveram as técnicas de citrometria de fluxo, microdiálise, HPLC, dosagem radiométrica de atividade enzimática, PCR em tempo real e western blot. Os resultados encontrados mostraram que o diabetes causa diminuição $(50 \%)$ e perda do perfil mono/bifásico da síntese pineal de melatonina em ambos dias de estudo. Essa queda não é causada por necrose ou apoptose dos pinealócitos, e reflete um desarranjo no metabolismo pineal que se evidenciou mais claramente pela diminuição pronunciada na atividade da AANAT (55\%), resultando diretamente no importante decréscimo observado na síntese do referido indol. Essa redução apresentou-se acompanhada de um desbalanço rítmico de fatores determinantes para o processo, como a expressão do receptor $\beta 1$ e a atividade e expressão das enzimas TPH1 e HIOMT. Além disso, podem ter contribuído de forma importante para o quadro observado tanto a queda da produção de leptina quanto de insulina, intrínsecas ao quadro do diabetes induzido pela estreptozotocina. A menor concentração de melatonina circulante pode ser um fator contribuinte e fundamental para o estabelecimento e desenvolvimento da doença, não só por diminuir a capacidade do organismo de combater o estresse oxidativo, mas também por provocar alterações na organização rítmica circadiana e prejudicar o importante papel exercido pela melatonina na potenciação da ação da insulina.

Palavras-chave: Melatonina. Pineal. Diabetes. Estreptozotocina. AANAT. Microdiálise. 


\begin{abstract}
AMARAL, F. G. Pineal melatonin production in Streptozotocin-diabetic rats: mechanisms and microdialysis daily profile. 2009. 181 p. Doctorade Thesis (Physiology) Instituto de Ciências Biomédicas, Universidade de São Paulo, São Paulo, 2009.

Melatonin is mainly synthesized by the pineal gland in a strictly nocturnal pattern. The resulting increase in circulating melatonin provides a signal of night time and is used to optimally synchronize physiological functions, including the energy metabolism, to daily changes in the environment. Diabetes mellitus is a syndrome characterized by disordered metabolism and hyperglycemia resulting from either a progressive loss in insulin secretion and/or from abnormal resistance to insulin's effects. Evidences in the literature show that melatonin is involved in the regulation of insulin synthesis and secretion, as well as in the peripheral sensitivity to this hormone. On the other hand, insulin was shown to increase melatonin synthesis induced by norepinephrine. Considering the possibility of a crosstalk involving both hormones, the controversial available data on melatonin synthesis and diabetes, and the lack of information on the status of the molecular mechanisms involved in melatonin synthesis in diabetic rats, this study was designed to analyze the daily pineal melatonin production in streptozotocin-diabetic male Wistar rats $(60 \mathrm{mg} / \mathrm{kg}$, i.p. $)$, as well as the activity pattern and gene expression profiles of the enzymes involved in this process. The animals (240-280 g) were kept under a 12-hr light/12-hr dark cycle in a temperaturecontrolled room $\left(21 \pm 2{ }^{\circ} \mathrm{C}\right)$, with water and food ad libitum. Diabetes was determined by tail blood glucose measurement and the animals were sacrificed on day 3 and day 15 after induction. The techniques used here include flow cytometry, microdialysis, HPLC, enzyme activity assay, qPCR and Western blot. The results show that pineal melatonin production is decreased $(50 \%)$ in streptozotocin-induced diabetic animals, both 3 and 15 days after induction, with an additional loss in the mono/biphasic circadian profile. These alterations were not due to necrosis or apoptosis in the pinealocytes, but to impairment in the pineal metabolism that involved the important decrease in the AANAT activity (55\%), resulting in the observed indolamine synthesis reduction. In addition, other key factors involved in melatonin production presented an imbalance in the rhytmic profile, such as the B1-adrenergic receptor gene expression and the TPH1 and HIOMT genes expressions and activities. Besides that, the already known decrease in circulating insulin and leptin levels in diabetic animals may also have a role in the observed melatonin synthesis reduction. This decrease may contribute to the development of diabetes and its cronic effects by undermining the organism capability of overcoming the oxidative stress derived from the disease. Future studies should include melatonin rhythmically reposition to check if it would be able to diminish some of the symptoms, as well as insulin treatment to try to restore melatonin levels.
\end{abstract}

Key words: Melatonin. Pineal. Diabetes. Microdialysis. AANAT. Streptozotocin. 


\section{INTRODUÇÃO}

\subsection{Glândula Pineal}

A identificação da pineal como um órgão distinto do cérebro remonta aos séculos III e IV AC, seu nome foi dado por Galeno de Pérgamo (130-200 DC) que também foi o primeiro a descrever sua localização. Várias foram as interpretações do seu papel funcional, que incluem desde um esfíncter controlador do fluxo do "espírito animal" até a interpretação cartesiana de "sede da alma" (ARENDT, 1995).

O órgão pineal origina-se embriologicamente, assim como a retina, de uma evaginação da parede do III ventrículo constituindo, junto com os núcleos habenulares, a maior parte do epitálamo (EKSTRÖM e MEISSL, 2003).

Em humanos a glândula pineal localiza-se na margem posterior do teto do diencéfalo e acima dos colículos superiores, mantendo relação anatômica com o terceiro ventrículo através do recesso pineal e ligando-se ao cérebro pelo pedúnculo pineal. Seu formato assemelha-se ao de uma "pinha", apresentando variações no seu peso (média de $129 \mathrm{mg}$ ) e tamanho (média de $12 \mathrm{~mm}$ ) dependendo da idade considerada. Em ratos o complexo pineal consiste basicamente de 3 partes: pineal profunda, pedúnculo pineal e pineal propriamente dita ou pineal superficial. Esta mede aproximadamente $2 \mathrm{~mm}$ e pesa $1,5 \mathrm{mg}$, localizando-se sobre os colículos superiores, no espaço entre o cérebro e o cerebelo, mantendo relação anatômica com o diencéfalo e com o terceiro ventrículo através do pedúnculo e da pineal profunda (VOLLRATH, 1981).

A análise evolutiva da glândula mostra que de maneira geral (mas não incluindo todas as espécies) aves, répteis, anfíbios e peixes apresentam pineal diretamente fotossensível. Nota-se, ainda, que o tipo celular majoritário do corpo pineal, o pinealócito, teve uma evolução conjunta com a irradiação dos vertebrados, com uma perda gradual da função fotorreceptora e um aumento da função neuroendócrina presente em todos esses animais (COLLIN, 1969, 1971; OKSCHE, 1971; COLLIN e OKSCHE, 1981). Assim, nos mamíferos o órgão perde sua capacidade fotorreceptiva e passa a estar sob o controle do sistema nervoso central, notadamente do simpático cervical. Dessa forma, as influências do ciclo de iluminação ambiental passam a se dar de forma indireta, através de projeções da retina para estruturas diencefálicas e destas para os neurônios pré-ganglionares que, através da inervação simpática periférica, atingem a glândula pineal (VOLLRATH, 1981; KORF, 2000). 
O controle da função hormonal da glândula é feito pelo ciclo dia-noite. Tal controle é bastante refinado, sendo o hormônio melatonina produzido durante a noite independentemente do ritmo de atividade da espécie considerada. Dessa forma, a melatonina circulante tem também seu perfil plasmático variável de acordo com as noites mais longas ou mais curtas típicas das diversas estações do ano (REITER, 1993). Fica claro assim a função fisiológica da glândula pineal: sinalizar para o meio interno pela presença e ausência diária da melatonina na circulação e nos diversos líquidos corpóreos, se é noite ou dia no meio exterior e, através da duração do seu perfil secretório noturno, qual é a estação do ano.

Outro papel importante que tem de ser considerado é que o perfil plasmático diário da melatonina apresenta uma variação característica ao longo do desenvolvimento ontogenético dos mamíferos, quais sejam: a sua produção e secreção são máximas na infância, apresentam uma pequena redução na puberdade, estabilizam-se na fase adulta, reduzindo consideravelmente em idosos. Essas características de produção e secreção da melatonina pela pineal fazem dela um importante marcador temporal ontogenético, promovendo processos adaptativos desde a infância até a velhice (CIPOLLA-NETO e AFECHE, 2008).

Em função desse papel de temporizador do meio interno, evidencia-se que a glândula pineal, através da secreção da melatonina, possa estar envolvida na regulação das mais diversas funções fundamentais para a sobrevivência do indivíduo e da espécie: regulação endócrina em geral e metabólica e reprodutiva em particular; regulação do ciclo atividaderepouso, em particular do sono e da vigília; regulação do sistema imunológico, regulação cardiovascular, entre outras.

Existem outros locais de síntese da melatonina, tais como retina e sistema gastrintestinal, entretanto acredita-se que a melatonina sintetizada nestas regiões tem maior importância na modulação de fenômenos locais (ARENDT, 1995).

\subsection{Melatonina}

Lerner et al. (1958) isolaram algumas microgramas de uma substância que mostrou atividade biológica em melanócitos de sapos, denominando-a melatonina.

A melatonina ( $N$-acetil 5-metoxitriptamina) é uma indolamina de peso molecular 232,3, sintetizada a partir do aminoácido essencial triptofano que é transformado em 5hidroxitriptofano pela triptofano hidroxilase 1 (TPH1, EC 1.14.16.4), este passa por uma descarboxilação subseqüente catalisada pela descarboxilase de 1-aminoácidos aromáticos (EC 4.1.1.28) que resulta na formação de serotonina. A serotonina é, por sua vez, acetilada pela 
ação da arilalquilamina $\mathrm{N}$-acetiltransferase (AANAT, EC 2.3.1.87) e transformada em Nacetilserotonina, que tem o grupamento hidroxila trocado por metil pela ação da hidroxindoloxi-metiltransferase (HIOMT, EC 2.1.1.4), culminando na formação da melatonina (CIPOLLA-NETO et al., 1999) (Figura 1).

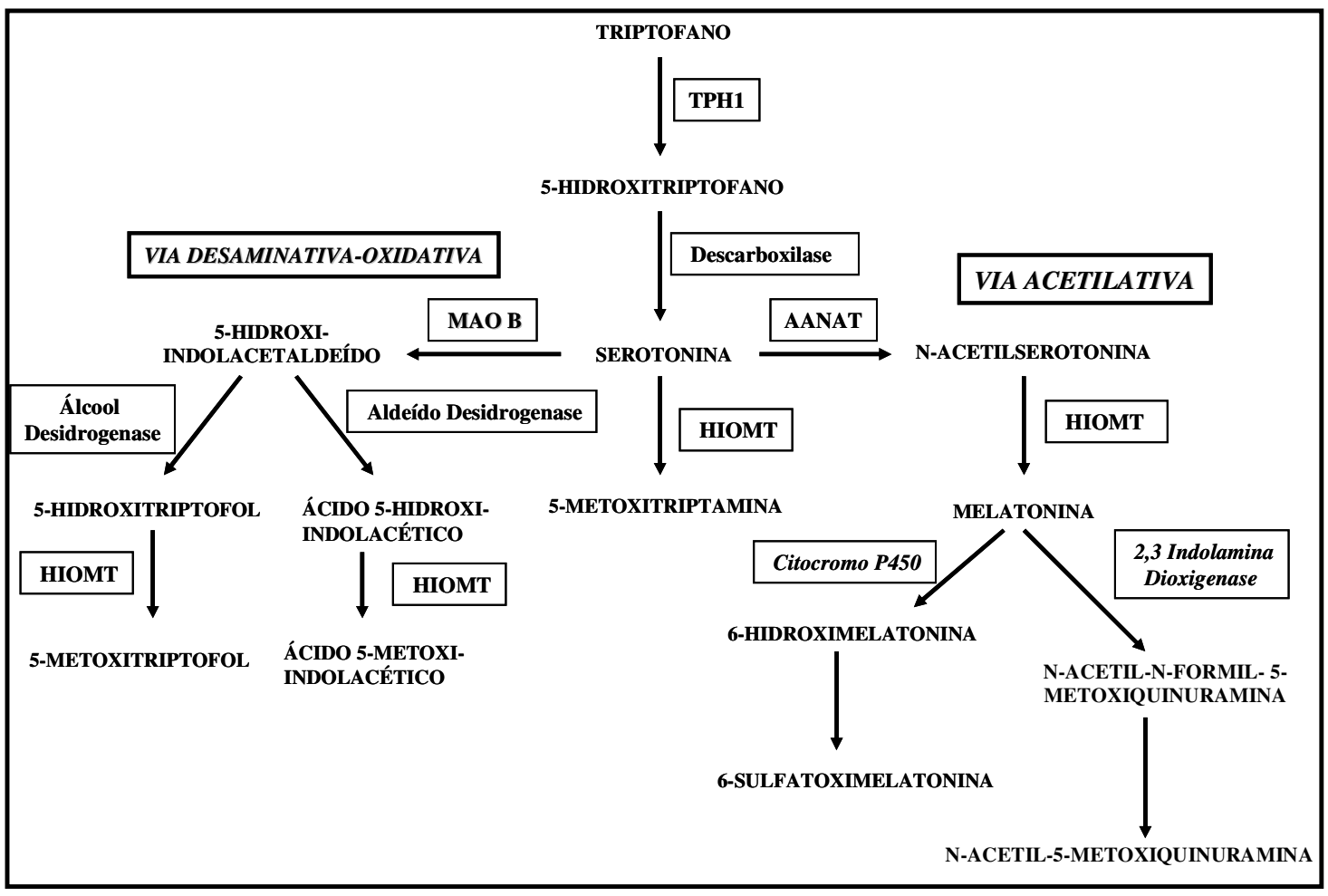

Figura 1. Vias metabólicas de síntese e degradação da melatonina e de outros indóis na glândula pineal (Adaptado de CIPOLLA-NETO e AFECHE, 2008).

O sistema neural que controla o metabolismo da glândula pineal origina-se no núcleo paraventricular do hipotálamo que se projeta para coluna intermédio-lateral da medula torácica alta, nos neurônios pré-ganglionares do sistema nervoso autônomo simpático. Estes neurônios projetam-se então para os gânglios cervicais superiores, cujos neurônios pósganglionares se projetam para glândula pineal através dos ramos carotídeos internos e nervos conários. O ritmo diário de síntese de melatonina depende do sistema neural que controla a ritmicidade circadiana e que começa na retina e se projeta via trato retino-hipotalâmico, principalmente para o núcleo supraquiasmático que se conecta com o núcleo paraventricular hipotalâmico, controlando nas 24 horas a atividade da via neural descrita acima (CIPOLLANETO e AFECHE, 2008) (Figura 2). 


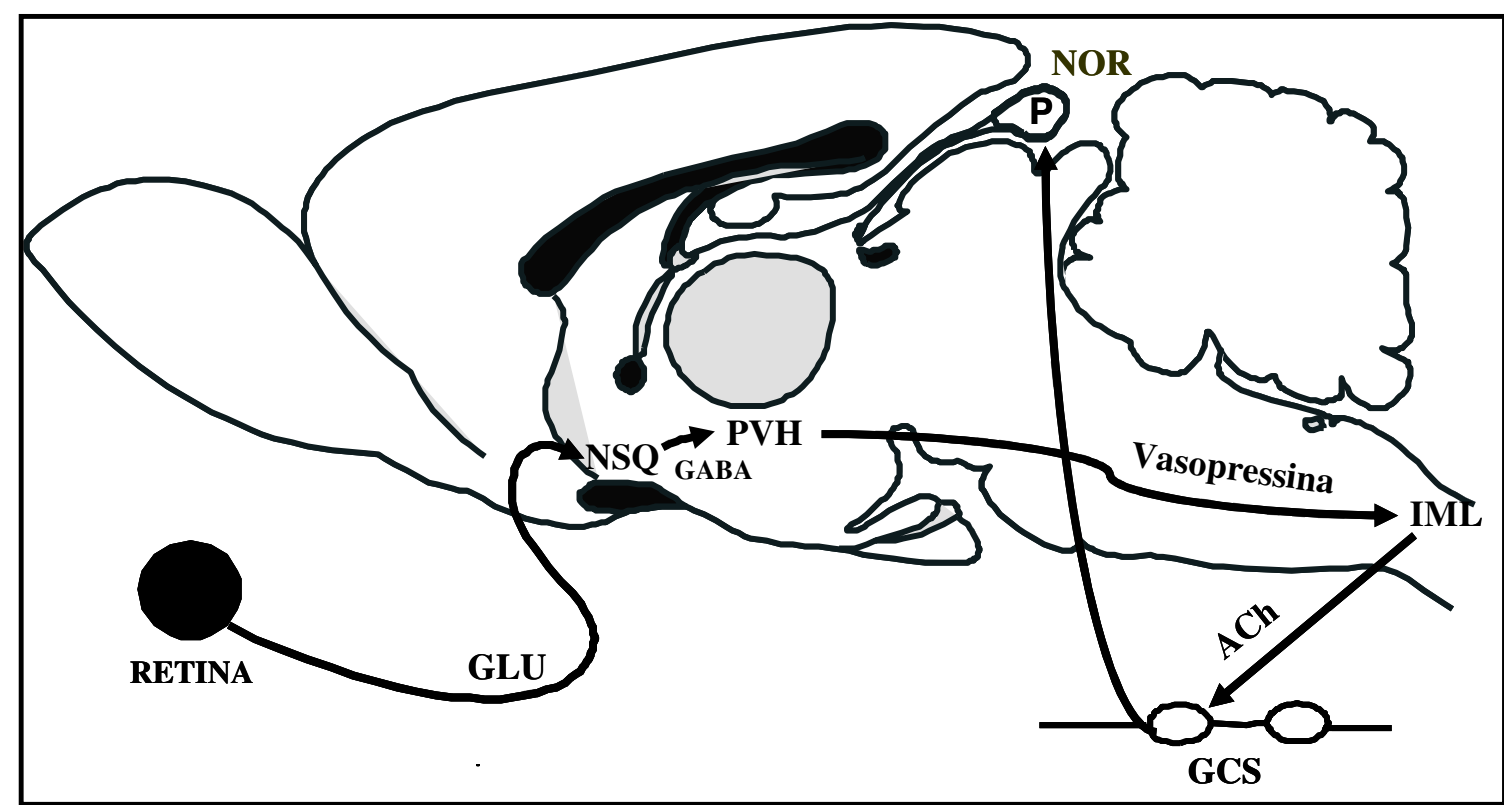

Figura 2. Vias neurais do controle diário da síntese de melatonina pineal e os principais neurotransmissores envolvidos. GLU: glutamato; NSQ: núcleo supraquiasmático; GABA: ácido gama-aminobutírico; PVH: núcleo paraventricular hipotalâmico; IML: coluna intermédio-lateral da medula espinhal; Ach: acetilcolina; GCS: gânglio simpático cervical superior; P: pineal; NOR: noradrenalina (Adaptado de CIPOLLA-NETO e AFECHE, 2008).

A ativação noturna da via neural de projeção periférica para a glândula pineal induz a liberação de noradrenalina nas proximidades dos pinealócitos, os quais apresentam receptores $\alpha$ e $\beta$-adrenérgicos. Da interação com os receptores $\beta$ (subtipo $\beta_{1}$ ) há a indução do aumento do AMPc intracelular através da ativação de proteína $\mathrm{G}$ estimulatória (Gs) e da enzima adenilato ciclase. A ativação dos receptores $\alpha$ (subtipo $\alpha_{1 \mathrm{~B}}$ ) ativa a proteína $\mathrm{Gq}$ ligada à estimulação da fosfolipase $\mathrm{C}$, gerando $\mathrm{IP}_{3}$ e diacilglicerol. $\mathrm{O} \mathrm{IP}_{3}$, atuando em seus receptores no retículo endoplasmático, induz a liberação do cálcio desses estoques, tendo como conseqüência um aumento do cálcio intracitoplasmático (KLEIN, 1985; VANECEK et al., 1985).

O aumento do cálcio induzido por noradrenalina caracteriza-se por um pico seguido de um platô. A rápida elevação do cálcio deve-se à liberação do retículo (SCHAAD et al., 1995) e o platô que se segue parece dever-se à entrada de cálcio pelos canais da membrana plasmática responsáveis pela reposição dos estoques intracelulares (GOMPERTS et al., 2002).

O cálcio e o diacilglicerol ativam a proteína quinase $\mathrm{C}$ (PKC) que potencia o aumento do AMPc já induzido pela estimulação $\beta$-adrenérgica. Este efeito pode ocorrer pela fosforilação da adenilato ciclase ou da proteína Gs (KLEIN et al., 1983; SUGDEN, 1989; SUGDEN et al., 1985, 1986, 1987). O cálcio tem um papel potenciador da síntese do AMPc intracelular também por atuar através do complexo cálcio/calmodulina na ativação da 
adenilato ciclase, que na glândula pineal foi caracterizada como do tipo 1 (ANHOLT, 1994; TZAVARA et al., 1996).

A enzima triptofano hidroxilase 1 (TPH1) é responsável pela transformação de triptofano em 5-hidroxitriptofano e é a enzima passo-limitante na síntese da serotonina. A concentração de triptofano na pineal é maior do que em qualquer parte do sistema nervoso central. O transporte de triptofano no sistema nervoso central se dá através de um sistema de transporte de aminoácidos neutros, e um sistema semelhante a esse poderia estar carregando o triptofano para dentro dos pinealócitos (SUGDEN et al., 1989). A enzima não parece estar saturada com relação ao seu substrato uma vez que a administração de triptofano produz um aumento dos níveis de serotonina na pineal (YOUNG e ANDERSON, 1982).

$\mathrm{Na}$ glândula pineal do rato, a enzima TPH1 apresenta um ritmo circadiano de atividade com valores mais elevados no período noturno. Esse aumento da atividade de cerca de 2 vezes durante à noite deve-se tanto à sua síntese aumentada, pela indução de transcrição gênica e síntese protéica, como à ativação da enzima por fosforilação (BESANÇON et al., 1996; SITARAM e LEES, 1978; SHIBUYA et al., 1978). Tanto o ritmo do RNAm da TPH1, como o ritmo de atividade da enzima são induzidos por estimulação noradrenérgica, via AMPc e proteína quinase A (PKA). A PKA, por mecanismo independente do CREB, promove a transcrição da referida enzima (BOADLE-BIBER, 1980; EHRET et al., 1991; SHEIN e WURTMAN, 1971; SITARAM e LEES, 1984). A fosforilação da TPH1 pode ser feita pela PKA, pela quinase dependente de cálcio-calmodulina (CaMK) e pela PKC (EHRET et al., 1989, 1991; JOHANSEN et al., 1995, 1996; KUHN et al., 1978).

A regulação da atividade da TPH1 também é feita através de sua associação com a proteína 14-3-3. A TPH1 fosforilada pela CaMK, PKC ou pela PKA liga-se à proteína 14-3-3, aumentando a sua atividade e impedindo a sua desfosforilação (ICHIMURA et al., 1987; BANIK et al., 1997; KLEIN et al., 2003). Baltatu et al. (2000) demonstraram que a expressão da TPH1 também é influenciada pela ação da Angiotensina II em receptores do tipo AT $_{1}$.

A atividade da enzima TPH1 é dependente de oxigênio e requer a pteridina reduzida como co-fator (FRAZER e HENSLER, 1994). Ainda, a sua atividade pode ser estimulada por $\mathrm{Fe}^{2+}$ e ditiotreitol, e pelos fosfolipídeos de membrana através da indução de sua associação à membrana plasmática (HAMON et al., 1978; IMAI et al., 1989; KUHN et al., 1978).

A concentração de serotonina na glândula pineal é mais alta do que em qualquer outro tecido, apresentando variação circadiana, com altas concentrações durante o período claro e baixas concentrações no período escuro (KLEIN et al., 1992; MEFFORD et al., 1983). A enzima conversora do 5-hidroxitriptofano em serotonina, a descarboxilase de L-aminoácidos 
aromáticos, parece ser a mesma que atua na descarboxilação da L-DOPA produzindo dopamina (FRAZER e HENSLER, 1994).

Durante o dia o metabolismo da serotonina é desviado para a via desaminativaoxidativa onde sofre a ação da MAO (EC 1.4.3.4.; monoamina: O2 oxidoredutase), sendo transformada em 5-hidroxi-indolaldeído, que sob a ação da aldeído desidrogenase (EC 1.2.1.3) transforma-se em ácido 5-hidroxi-indolacético ou sob ação da álcool desidrogenase (EC 1.1.1.2) transforma-se em 5-hidroxitriptofol. Estes dois produtos podem ser O-metilados sob a ação da HIOMT, produzindo respectivamente o ácido 5-metoxi-indolacético e 5metoxitriptofol (KLEIN et al., 1981) (Figura 1).

A enzima arilalquilamina $\mathrm{N}$-acetiltransferase (AANAT) é responsável pela conversão de serotonina em $\mathrm{N}$-acetilserotonina, sendo considerada a enzima mais importante na via de síntese da melatonina por apresentar pronunciado ritmo circadiano de atividade dependente da estimulação noradrenérgica (KLEIN e WELLER, 1972, KLEIN et al., 1992).

Como já mencionado, no rato o AMPc, resultante da estimulação do receptor $\beta_{1}$ adrenérgico, ativa a proteína quinase A do tipo II (PKA) (MARONDE et al., 1999), que fosforila o fator de transcrição CREB, promovendo a ativação das transcrição e tradução de vários genes importantes no metabolismo pineal, dentre eles o da AANAT. A ativação da AANAT é resultado de sua fosforilação pela PKA em dois sítios específicos localizados no N-terminal e no C-terminal e subseqüente ligação com a proteína 14-3-3, formando o complexo AANAT/14-3-3 que além de ativar a enzima, a protege da proteólise proteassomal (GANGULY et al., 2001; KLEIN et al., 1996; KOCH et al., 2003; ROSEBOOM e KLEIN, 1995; TAMOTSU et al., 1995).

Quando a estimulação adrenérgica cessa, ou quando se administram antagonistas adrenérgicos ou se submete o animal a uma fotoestimulação no meio da noite, a atividade da AANAT cai com uma meia vida de aproximadamente 3 min (CIPOLLA-NETO e AFECHE, 2008; DEGUCHI e AXELROD, 1972; KLEIN e WELLER, 1972; KLEIN et al., 1978; PARFITT et al., 1976).

Em algumas espécies de mamíferos, como ovinos e primatas, o principal mecanismo de ativação da AANAT se dá pela inibição da proteólise proteassomal à noite, sendo muito pequena a variação diária do RNAm da enzima (GARIDOU et al., 2001; GASTEL et al., 1998).

A estimulação adrenérgica induz também a síntese de fatores de transcrição negativos na glândula pineal, sendo um dos mais importantes o ICER ("inducible cAMP early repressor"), que tem um papel inibitório da transcrição do gene da AANAT. O RNAm do 
ICER exibe um ritmo circadiano na pineal do rato, com um pico na segunda metade da noite que precede o declínio da síntese de melatonina. Além do ICER, o AMPc estimula a síntese de outros fatores de transcrição negativos como o Fra-2 ("Fos-related antigen-2") e JunB que também poderiam estar promovendo a queda circadiana da atividade da AANAT (BALER e KLEIN, 1995; SPESSER et al., 2000).

O passo final da produção consiste na transformação de N-acetilserotonina (NAS) em melatonina catalisada pela enzima hidroxindol-oxi-metiltransferase (HIOMT) (CIPOLLANETO e AFECHE, 2008).

A HIOMT, enzima pertencente à família das metiltransferases, catalisa a reação de transferência de um grupamento metil, proveniente do cofator S-adenosil-L-metionina (SAM), para seu substrato indólico. Essa metilação se dá não só tendo como substrato a Nacetilserotonina (afinidade de 50-80\%), mas também é realizada tendo como substratos outros indóis presentes na pineal, tais como: 5-hidroxitriptofano (afinidade menor que 5\%), 5hidroxitriptamina (serotonina, 10\% de afinidade), ácido 5-hidroxindolacético (afinidade menor que 5\%) e 5-hidroxitriptofol (15-30\% de afinidade) (AXELROD e WEISSBACH, 1961).

A atividade da HIOMT no período noturno apresenta um aumento de 1,5 vezes, enquanto o seu RNAm tem um aumento de 2 vezes (RIBELAYGA et al., 1999; SIMONNEAUX e RIBELAYGA, 2003).

Os mecanismos envolvidos na regulação desta enzima são complexos e não estão totalmente elucidados. Por um lado o ritmo circadiano do RNAm da HIOMT é dependente da estimulação adrenérgica, da ativação do receptor $\beta$-adrenérgico e do aumento na concentração de AMPc. Já a regulação do ritmo de atividade da referida enzima parece ser dependente de eventos pós-transcricionais, induzidos por neurotransmissores que aumentam o cálcio (SIMONNEAUX et al., 1999).

O NPY tem efeito estimulatório sobre a atividade da HIOMT, potenciando a síntese de melatonina (RIBELAYGA et al., 1997). Estudos in vivo demonstraram que a atividade da HIOMT é significantemente correlacionada com a concentração do NPY, que tem um ritmo diário e sazonal. Verificou-se também que o aumento noturno do RNAm da HIOMT não tem relação direta com o aumento da atividade da mesma (SIMONNEAUX et al., 1999).

A regulação adrenérgica da atividade da HIOMT parece ocorrer em longo prazo, pois trabalhos com animais expostos à luz constante ou que tiveram removidos os seus gânglios cervicais superiores mostraram que houve uma redução na atividade da HIOMT, mas os níveis basais do RNAm da enzima não estavam alterados (SUGDEN et al., 1989). 
Costuma-se considerar que toda melatonina produzida é imediatamente secretada, seja pela sua alta lipossolubilidade, seja pelo fato de ela não poder ser detectada por métodos histoquímicos celulares em grânulos de secreção nos pinealócitos. No entanto, há evidências que a secreção de melatonina poderia ser regulada de forma independente da sua síntese. Assim, demonstra-se em várias espécies que a secreção de melatonina (cuja concentração plasmática é medida tanto na grande confluência venosa posterior quanto perifericamente) tem caráter pulsátil, com a freqüência, em ratos, de aproximadamente 2,9 ciclos por hora. Apesar desse ritmo de secreção poder ser atribuído a eventuais alças bioquímicas envolvidas na síntese da melatonina ou a outros fatores, poderia, também, ser atribuída a um processo de armazenagem, uma vez que parecem independer do padrão de descarga das fibras simpáticas aferentes. Mesmo em glândulas mantidas em cultura e submetidas à técnica de perfusão, há evidencias de secreção pulsátil de melatonina induzida por agonistas beta-adrenérgicos. Além disso, algumas substâncias como adenosina, dopamina e bloqueadores de canais de cálcio parecem regular o processo de secreção de melatonina pelos pinealócitos (CIPOLLA-NETO e AFECHE, 2008).

A melatonina é liberada nos espaços perivasculares da glândula, difundindo-se para a circulação. Em ratos a melatonina liquórica parece vir tanto através da circulação sanguínea quanto por secreção direta da glândula no recesso pineal. O seu transporte plasmático se dá principalmente ligado à proteínas, em especial a albumina (CARDINALI et al., 1972; CARDINALI e VACAS, 1987).

A concentração plasmática no momento do pico noturno é, no rato, de aproximadamente $100 \mathrm{pg} / \mathrm{mL}\left(0,43 \times 10^{-9} \mathrm{M}\right)$ (VOLLRATH, 1981). No entanto, deve-se ter cuidado ao considerar esta como a única dose "fisiológica", uma vez que em certos tecidos e compartimentos a melatonina pode ser encontrada em concentrações mais altas (até 100 a 1000 vezes maior), como no líquor, por exemplo (REITER e TAN, 2003).

A vida média da melatonina circulante é de aproximadamente 20 minutos em ratos e de 44 minutos em humanos (PANG et al., 1993), sendo que sua metabolização periférica se dá essencialmente pela transformação hepática (aproximadamente $90 \%$ da melatonina circulante) em 6-hidroximelatonina que após conjugação com sulfatos (a maior parte) ou com glucoronídeos é excretada na urina. O metabólito urinário, 6-sulfatoximelatonina, é um importante elemento a ser usado em estudos clínicos não invasivos. No sistema nervoso central e na própria glândula pineal a melatonina pode ser transformada em quinuraminas sob a ação da 2,3 indolamina dioxigenase (YU et al., 1993). 
As características químicas da molécula da melatonina ( $\mathrm{N}$-acetil-5-metoxitriptamina, Figura 3), pela presença dos grupamentos metoxi no carbono 5 e do grupamento acil ligado ao nitrogênio do grupo amina, são de anfifilicidade. Ou seja, ela tem a propriedade de difundir-se com igual capacidade tanto em meios hidrofílicos quanto lipofílicos. Além disso, os carbonos 2 e 3 do anel pirrólico possuem uma alta capacidade de doar elétrons. Isso confere a melatonina uma pronunciada capacidade antioxidante (CIPOLLA-NETO e AFECHE, 2008).

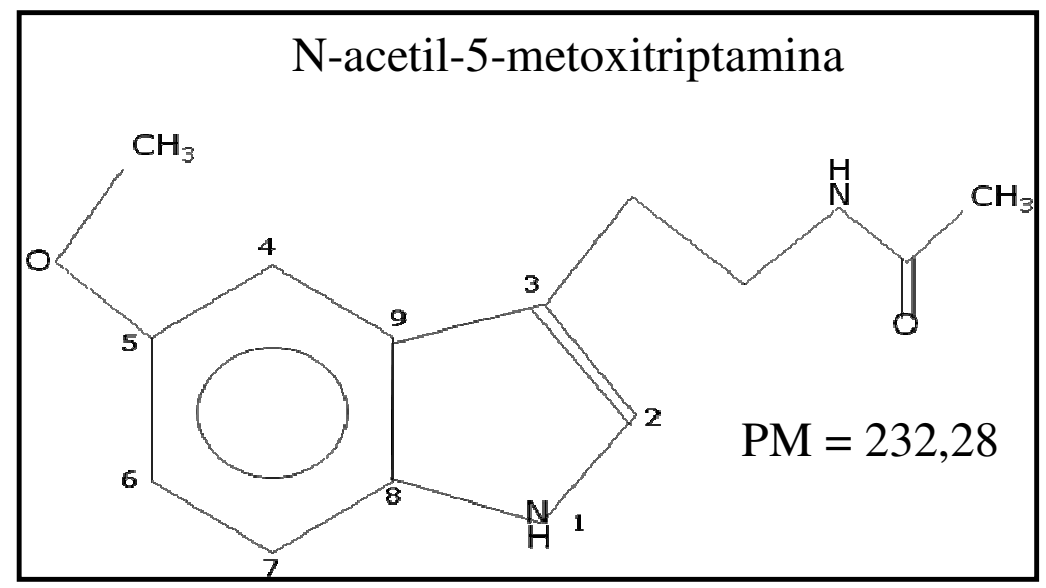

Figura 3. Estrutura química da melatonina (Adaptado de CIPOLLA-NETO e AFECHE, 2008).

A melatonina desempenha diversas funções nos seres vivos, além da sinalização circadiana e do papel de antioxidante, que podem ou não ser mediadas por receptores. A interação direta da melatonina com outras moléculas dá a ela a capacidade de agir mobilizando mecanismos reparadores do DNA e regulando o processo de apoptose celular (MAYO et al., 1998); além de regular diretamente a ação de diversas enzimas (ligando-se à cálcio-calmodulina e bloqueando quinases dela dependentes, por exemplo), regulando também o metabolismo oxidativo e o transporte de elétrons pela sua ação intra-mitocondrial (REITER et al., 2004).

Nos mamíferos estão bem caracterizados três tipos de receptores de membrana para melatonina (DUBOCOVICH, 1995). Os receptores de alta afinidade $\mathrm{MT}_{1}$ e $\mathrm{MT}_{2}$ pertencem à superfamília dos receptores ligados à proteína $\mathrm{G}$, ligando-se à proteína $\mathrm{G}_{\mathrm{i}}$ e promovendo uma redução na produção do AMPc (MORGAN et al., 1994). O receptor $\mathrm{MT}_{1}$, além de ligar-se à $\mathrm{G}_{\mathrm{i}}$, tem afinidade pela proteína $\mathrm{G}_{\mathrm{q} / 11}$ que lhe confere a característica de poder aumentar a produção de diacilglicerol e $\mathrm{IP}_{3}$, podendo resultar em maior concentração intracelular de cálcio e atividade da PKC (BARRETT et al., 1996). Por outro lado, está demonstrado em vários sistemas que a melatonina, mediada pelo receptor $\mathrm{MT}_{1}$, pode ativar correntes 
retificadoras de potássio, diminuindo a despolarização celular e resultando em uma redução do influxo de cálcio através dos canais de cálcio dependentes de voltagem. Os mecanismos mobilizados pela $G_{i}$ quando o receptor $\mathrm{MT}_{2}$ é ativado podem resultar em uma redução do GMPc, além de implicar na mobilização de dois mecanismos de transdução intracelular: um dependente do componente $\alpha$ (inibição da adenilato ciclase) e outro dependente do componente $\beta \gamma$, resultando na ativação da fosfolipase C (REPPERT et al., 1995).

Os receptores de alta afinidade estão distribuídos por todo o organismo desde o sistema nervoso central, onde está presente em várias estruturas, até órgãos e tecidos da periferia (PANG et al., 1993).

O terceiro tipo de receptor de membrana para melatonina existente em mamíferos é o $\mathrm{MT}_{3}$, um receptor cuja estrutura molecular é muito parecida com uma enzima, a quinona redutase, e cujas ações não estão completamente esclarecidas (REPPERT et al., 1996).

O receptor nuclear conhecido para a melatonina é um dos receptores órfãos da família dos receptores de ácido retinóico do tipo RZR/ROR (PARK et al., 1997). Alguns dos efeitos atribuídos a essa interação são a expressão da enzima lipo-oxigenase, a expressão das enzimas antioxidantes e a síntese de interleucina 2 (CARLBERG e WIESENBERG, 1995).

\subsection{Diabetes Mellitus}

A International Diabetes Federation (IDF) estima que mais de 245 milhões de pessoas em todo mundo têm diabetes, sendo que a expectativa é de que esse número cresça para 380 milhões em 20 anos. A cada ano, 7 milhões de pessoas desenvolvem os sintomas de diabetes em todo mundo (IDF, 2009). A mesma instituição estima que em 2007 havia no Brasil 6.913.300 pessoas com diabetes com idades entre $20-79$ anos (5,8\% da população na mesma faixa etária), com projeção de aumento para 11,4\% em 2025 (IDF, 2007).

O Estudo Multicêntrico sobre a Prevalência do Diabetes Mellitus no Brasil, também conhecido como "Censo Brasileiro de Diabetes", avaliou a prevalência do diabetes no período de 1986 a 1988 em nove capitais brasileiras (Porto Alegre, São Paulo, Rio de Janeiro, Brasília, Salvador, Recife, João Pessoa, Fortaleza e Belém), através de medidas diretas de glicemias realizadas em domicílios sorteados ao acaso. A prevalência, detectada na faixa etária de 30 a 69 anos, foi de 7,6\% para o diabetes e de 7,8\% para a tolerância diminuída à glicose (MALERBI e FRANCO, 1992).

Entre 1996 e 1997, cerca de 10 anos após o Censo Brasileiro de Diabetes, Torquato et al. (2003) conduziram novo estudo sobre prevalência de diabetes e de tolerância diminuída à 
glicose na população de Ribeirão Preto, empregando a mesma metodologia do Censo Brasileiro de Diabetes. Os dados de Ribeirão Preto mostraram uma prevalência de $12,1 \%$ de diabetes e de 7,7\% de tolerância diminuída à glicose na faixa etária de 30 a 69 anos, ou seja, um aumento de $59 \%$ na prevalência de diabetes e a manutenção de prevalência equivalente de tolerância diminuída à glicose. A Sociedade Brasileira de Diabetes considera que a cifra de 12\% apontada pelo estudo de Ribeirão Preto para a faixa etária de 30 a 69 anos seja provavelmente a que melhor reflete a situação atual no Brasil.

A American Diabetes Association (ADA) estimou em US\$132 bilhões os gastos com diabetes em 2002 nos Estados Unidos, com previsão de aumento para US\$192 bilhões em 2020 (WHO e IDF, 2006). Estimativas do custo direto para o Brasil estão em torno de 3,9 bilhões de dólares americanos, em comparação com 0,8 bilhão para a Argentina e 2 bilhões para o México (BARCELÓ et al., 2003).

O diabetes mellitus (DM) é um distúrbio metabólico complexo e primário dos carboidratos, que envolve secundária e importantemente, também lipídeos e proteínas. É caracterizado por hiperglicemia resultante da perda progressiva da secreção ou da ação da insulina (ZIMMET et al., 2001).

Independentemente da etiopatogênese da doença, a expressão fenotípica da deficiência de insulina ou de sua ação manifesta-se por ampla e variada ordem de distúrbios metabólicos, com pelo menos três formas de apresentação: (1) estado pré-diabético, caracterizado por retardo na liberação de insulina após ingestão de glicose, em indivíduo com tolerância normal para esta; (2) estado diabético latente, em que o metabolismo intermediário é normal ou quase normal, porém com hipoglicemia reativa após refeições e diminuição da tolerância à glicose; (3) diabete declarada, franca ou clínica, que se manifesta por hiperglicemia, outras alterações metabólicas e sinais e sintomas clínicos (THREATTE, 1999).

Os dois principais tipos de diabetes mellitus são o Tipo 1, que corresponde a 10 a $20 \%$ dos casos, e o Tipo 2, representando 80 a 90\% dos casos. Esses dois tipos distinguem-se pela apresentação clínica, origem genética, patogênese, lesões das ilhotas pancreáticas e resposta à insulina (CONTRERAS, 2004).

O diabetes Tipo 1, anteriormente conhecido como infanto-juvenil ou com início no crescimento, aparece com mais freqüência em faixas etárias jovens, podendo também apresentar-se em faixas etárias mais avançadas (3-50 anos). Resulta da deficiência parcial ou absoluta de insulina por supressão das células $\beta$, é sempre sintomático, manifestando-se por poliúria, polidipsia, emagrecimento, polifagia e cetoacidose. A secreção de insulina com o 
decorrer dos anos torna-se nula e o tratamento então envolve insulina exógena (WAJCHENBERG, 1992).

O diabetes mellitus tipo 1 manifesto é precedido por um período subclínico no qual ocorre uma destruição seletiva e progressiva de células $\beta$. Esse processo pode ser dividido em seis estágios: 1. suscetibilidade genética; 2. fatores precipitantes; 3. alterações imunológicas; 4. diminuição da secreção insulínica; 5. diabetes manifesto com secreção residual de insulina; e 6. diabetes instável com insuficiência total da secreção insulínica (TATTERSALL, 1972).

Este tipo de diabetes está relacionado com fenômenos de autoimunidade e apresentam positividade para certos antígenos do sistema HLA. Os marcadores de auto-imunidade são os auto-anticorpos: antiinsulina, antidescarboxilase do acido glutâmico (GAD 65) e antitirosinafosfatases (IA2 e IA2B) (PALMER et al., 1983; BAEKKESKOV et al.,1990; RABIN et al., 1994). Esses anticorpos podem estar presentes meses ou anos antes do diagnóstico clínico, ou seja, na fase pré-clínica da doença, e em ate $90 \%$ dos indivíduos quando a hiperglicemia é detectada. Alem do componente auto-imune, o DM1 apresenta forte associação com determinados genes do sistema antígeno leucocitário humano (HLA), alelos esses que podem ser predisponentes ou protetores para o desenvolvimento da doença (TODD et al., 1987).

A presença de alguns antígenos do sistema HLA, principalmente o DR3 e o DR4, conferem um risco maior para o desenvolvimento do diabetes mellitus tipo 1. Aproximadamente 95\% dos pacientes com essa moléstia são DR3 e/ou DR4 positivos, enquanto na população geral essa positividade é em torno de 40\% (NERUP, 1984). Como fatores precipitantes, os indivíduos sofreriam a ação de fatores ambientais que colaborariam no desencadeamento de mecanismos auto-imunológicos contra as células $\beta$. Os vírus são os mais prováveis desses fatores. Esses mecanismos imunológicos envolvem o aparecimento dos auto-anticorpos anti-ilhota e anti-insulina (WAJCHENBERG, 1992).

Os danos causados às ilhotas resultam em uma perda seletiva da resposta à glicose pelas células $\beta$ e conseqüente redução na produção de insulina. Ao aparecimento dos primeiros sinais clínicos do diabetes mellitus tipo 1, estima-se que mais de $90 \%$ das células $\beta$ já foram destruídas. A destruição completa determina a necessidade da administração da insulina exógena como parte importante do tratamento do paciente.

A incidência do diabetes Tipo 1 pode variar consideravelmente entre diferentes grupos raciais e regiões geográficas. As causas destas variações permanecem desconhecidas e estão possivelmente relacionadas a fatores genéticos e ambientais. Estes são sugeridos pela variação sazonal da freqüência de aparecimento da doença (CHRISTOY, 1977). A concordância para o 
diabetes tipo 1 em gêmeos univitelinos é menor que 50\%, sugerindo que fatores ambientais tem papel importante na eclosão da moléstia (TATTERSALL, 1972).

O diabetes mellitus Tipo 2, anteriormente denominado diabetes tipo adulto, ou diabetes com início na maturidade, consiste na diminuição da função das células $\beta$, ainda existindo porém certa capacidade de secreção insulínica, que pode resultar em pacientes com aumentos esporádicos e inconsistentes na insulina plasmática; além de envolver também a resistência periférica à insulina. A auto-imunidade não é demonstrável no diabetes tipo 2, e também não existe correlação com antígenos do sistema HLA (WAJCHENBERG, 1992).

O DM Tipo 2 manifesta-se, em geral, após os 30 anos e corresponde a 80-90\% dos casos de DM. Como regra, não depende da insulina exógena para seu controle ou para prevenção da cetoacidose, porém requer seu uso para correção da hiperglicemia persistente que não responde à dieta apropriada ou aos hipoglicemiantes orais (CONTRERAS, 2004).

A insulina plasmática mantém-se normal ou elevada, a obesidade é freqüente e a sua ausência indica uma forma distinta de diabetes não-insulino-dependente. A gliconeogênese está aumentada e o consumo de glicose periférica reduzido, determinando hiperglicemia de jejum e pós-prandial; em geral não há tendência à cetoacidose pela ausência de lipólise e cetogênese (HENRY, 1999).

As alterações metabólicas são menos acentuadas e de controle mais fácil do que no tipo 1, os pacientes podem iniciar o quadro clínico com poliúria e polidipsia, e mais de $50 \%$ deles são hipertensos e/ou apresentam alterações dos lipídeos plasmáticos.

O DM tipo 2 é uma doença complexa, de patogênese controvertida e heterogênea, embora alguns fatores e mecanismos sejam conhecidos: (1) caráter familial: a participação genética é mais expressiva do que no diabete tipo 1 e não se relaciona com os genes HLA, alguns genes parecem estar relacionados com resistência à insulina e com hiporreatividade das células $\beta$ à glicose, e ainda, a predisposição genética atua juntamente com fatores ambientais como sedentarismo e obesidade abdominal; (2) no início a insulina plasmática é normal, porém insuficiente para atender às flutuações da glicose por redução dos receptores celulares (resistência à insulina); (3) segue-se hiperinsulinismo discreto, secundário à resistência periférica à insulina e à constante estimulação pela hiperglicemia; (4) em seguida, ocorre diminuição discreta ou moderada da insulina por redução progressiva da função das células $\beta$, relacionada com o avançar da idade e com o esgotamento funcional que se segue à hiper-reatividade inicial (WAJCHENBERG, 1992). 


\subsection{Estreptozotocina e Indução do Diabetes Mellitus}

A estreptozotocina (STZ) é uma alquil-nitrosurea isolada originalmente a partir da bactéria Streptomycetes achromogenes, que apresenta propriedade antibiótica e antineoplástica (LEWIS, 1970) e é usada para indução experimental de diabetes mellitus. Sua estrutura molecular corresponde à molécula da 2-deoxi-D-glicose com uma substituição no carbono 2 que recebe um grupamento N-metil-N-nitrosuréia (HERR et al., 1967).

O diabetes experimental induzido pela STZ pode ser obtido tanto pela administração intraperitoneal quanto endovenosa da droga (DELFINO et al., 2002).

Schnedl et al. (1994) demonstaram que a toxicidade dirigida para as células $\beta$ é devida à similaridade da molécula de estreptozotocina à da glicose, o que permite que a mesma seja internalizada via transportadores GLUT2. A lesão das células ß foi confirmada por Junod et al. (1967 e 1969) que mostraram que a evidência histológica é observável entre uma e sete horas, sendo que após 24 horas o conteúdo de insulina dessas células está reduzido em 95\%. Outro mecanismo responsável pela especificidade da ação da STZ em células ß está relacionado ao aumento da glicosilação protéica pela inibição da O-GlcNac-seletiva N-acetilß-D-glicosaminoxidase (enzima que remove O-GlcNac das proteínas) que, no pâncreas é mais sensível à droga do que a mesma enzima em outros tecidos (KONRAD et al., 2001).

O dano às células $\beta$ por estreptozotocina ocorre principalmente pela formação de óxido nítrico decorrente da metabolização intracelular da droga. O óxido nítrico causa alquilação e fragmentação do DNA, que leva a apoptose (KRÖNCKE et al., 1995). Como conseqüência, a ativação aumentada da poli (ADP-ribose) polimerase (PARP) em resposta aos danos causados ao DNA provoca depleção intracelular de NAD+ e dos estoques de ATP, que podem colaborar para diminuição da síntese e secreção de insulina (LENZEN, 2008). Confirmando o papel do óxido nítrico, o bloqueio da sua produção nas ilhotas foi capaz de diminuir a fragmentação do DNA promovida pela STZ (BEDOYA et al., 1996).

Gille et al. (2002) reportaram que a geração de radicais hidroxila e de espécies reativas de oxigênio pela STZ podem também ser fatores cruciais no dano causado às células $B$, de modo que substâncias que interajam com radicais livres podem modular a ação da droga em diferentes tecidos.

A ação da droga nas células $\beta$ do pâncreas ocasiona mudanças na concentração plasmática de insulina e de glicose. Duas horas após a injeção observa-se hiperglicemia e queda brusca na insulinemia. Seis horas depois há hipoglicemia, devido a uma alta insulinemia. Logo a hiperglicemia fica totalmente estabelecida e o nível de insulina no sangue 
cai constantemente (WEST et al., 1996). Essas mudanças refletem a anormalidade no funcionamento das células $\beta$ pancreáticas.

A melatonina, devido a seu conhecido papel antioxidante, é capaz de proteger as células $\beta$ da ação da estreptozotocina, quando administrada dias antes da injeção da droga (ANDERSSON, 2001; YAVUZ et al., 2003).

\subsection{Melatonina e Metabolismo Energético}

Em trabalho pioneiro na área, Lima et al. (1994), relataram os primeiros resultados de experimentos com adipócitos isolados de tecido adiposo branco, incubados com melatonina, onde testou-se a capacidade desse hormônio regular a ação da insulina na captação de glicose. Os dados indicaram que a incubação prévia dos adipócitos com melatonina era suficiente para deslocar a curva dose $\mathrm{x}$ efeito, insulina x captação de glicose, para a esquerda, indicando que a melatonina aumentava a sensibilidade do tecido adiposo à ação da insulina.

Trabalhos conseguintes com animais pinealectomizados evidenciaram, pela primeira vez na literatura, que a pinealectomia leva a um quadro de resistência insulínica devido não a uma eventual alteração do receptor de insulina e seus primeiros passos de sinalização (fosforilação do IRS-1), mas sim a uma queda considerável (mais de 50\%) da quantidade de transportadores GLUT4 nas células dos tecidos adiposo e muscular. In vivo, a pinealectomia induziu uma dessincronização circadiana dos eventos metabólicos, de tal forma que os animais pinealectomizados perdem a capacidade de responderem a uma sobrecarga de glicose de acordo com a hora do dia. (LIMA et al., 1998; SERAPHIM et al., 1997).

A perda da eficiência celular de captação de glicose foi demonstrada por Martins Jr et al. (1998), em trabalho que evidenciou que a pinealectomia provocava uma queda do consumo de glicose e glutamina por leucócitos e macrófagos. Adicionalmente, entretanto, demonstrou-se, pela primeira vez, que a reposição terapêutica de melatonina era capaz de reverter esse quadro do animal pinealectomizado.

Zanquetta et al. (2003) mostraram, após a confirmação do estabelecimento de resistência insulínica em animais pinealectomizados (avaliada pelo ITT) e a queda na expressão de GLUT4 (avaliada tanto pela quantidade de proteína quanto de RNAm), que a reposição diária noturna de melatonina nesses animais provocava a reversão completa do quadro induzido pela pinealectomia. Demonstraram também, que a restrição calórica de $40 \%$ era capaz, a semelhança da melatonina, de reverter o quadro induzido pela pinealectomia. 
Alonso-Vale et al. (2004a) mostraram que a pinealectomia provoca resistência insulínica e hipercorticosteronemia independentemente da hora do dia, além de causar uma alteração dos parâmetros rítmicos metabólicos diários dos adipócitos, de forma a resultar num quadro de inadequação entre os requerimentos energéticos e a capacidade de mobilizá-los de acordo com o ciclo atividade-repouso. Esse mesmo efeito de desorganização rítmica metabólica provocada pela pinealectomia foi também constatado quando se considera a maior ou menor capacidade pancreática de secretar insulina frente a um estímulo glicêmico (PICINATO et al., 2002a).

Ainda na mesma linha de estudo, as respostas adaptativas ao jejum em animais pinealectomizados (ALONSO-VALE et al., 2004b) mostraram que a pinealectomia não provocou alteração da glicemia e insulinemia plasmáticas quando comparadas aos animais controles ao longo do jejum. No entanto, além de intensificar de forma considerável a corticosterolemia, induziu uma considerável queda da leptina plasmática. Da mesma maneira, a pinealectomia, como esperado, acentuou a resistência insulínica ao longo do jejum, ao mesmo tempo em que intensificou o estado catabólico de adipócitos in vitro, intensificando a oxidação de glicose e reduzindo a síntese de lipídeos. Dessa forma, a ausência da melatonina induz um quadro de resistência insulínica que piora com o jejum e um quadro de reajuste diminuído das respostas anabólicas dos adipócitos, que também se acentua com o jejum.

Outros estudos (BORGES-SILVA et al., 2005a, 2005b, 2007) mostram ainda que animais pinealectomizados não conseguem desenvolver as alterações metabólicas adaptativas ao treinamento físico aeróbio e, portanto, não apresentam o mesmo desempenho de animais controles treinados. Em conseqüência, não conseguem, pelo treinamento físico, reverter o quadro de resistência insulínica induzido pela pinealectomia, tanto no tecido adiposo quanto no tecido muscular.

Esse conjunto de dados mostra que a pinealectomia prejudica a capacidade de adaptação metabólica extremamente necessária para que o animal possa enfrentar condições estressantes (como exercício e jejum, por exemplo) e se adequar metabolicamente a estas situações. Ou seja, a ausência de melatonina nos animais pinealectomizados parece impedir as preparações metabólicas rítmicas circadianas típicas do período de atividade (adaptação ao exercício) ou do repouso (adaptação ao jejum). Além disso, a ausência de melatonina prejudica os ajustes rítmicos circadianos disparados pelos fatores associados à disponibilidade de alimentos (e as alterações metabólicas associadas) e a atividade física programada que, sabidamente, são importantes sincronizadores do relógio biológico circadiano. Essa 
incapacidade de ajuste rítmico, caracterizando uma dessincronização metabólica interna pode ser um dos responsáveis pelos desajustes acima citados.

Alonso-Vale et al. (2005) estudaram o mecanismo de regulação da expressão gênica, biossíntese e secreção de leptina em adipócitos isolados mantidos em cultura primária, tratada ou não com melatonina. Os dados revelam que a expressão gênica e a síntese de leptina só são estimuladas pela insulina desde que o tecido tenha sido exposto à melatonina, sugerindo um sinergismo entre os hormônios na estimulação do gene OB. O efeito combinado de insulina e da dexametasona não se revelou mais eficaz que o glicocorticóide sozinho, porém, quando se associou melatonina aos dois outros hormônios, a resposta de secreção de leptina superou a da associação dexametasona e melatonina. Estes dados mostram uma participação importante da melatonina sobre a regulação de expressão gênica de leptina bem como o seu papel modulador sobre a ação de outros hormônios.

Em estudos posteriores, Alonso-Vale et al. (2006 e 2008) mostraram que quando a incubação dos adipócitos isolados é feita com a adição rítmica de melatonina a cada $12 \mathrm{~h}$, os efeitos da insulina e da dexametasona na regulação da expressão e síntese da leptina se intensificam. Além disso, nesse tipo de cultura de adipócitos isolados in vitro com melatonina intermitente, foi possível sincronizar as funções básicas de lipólise e lipogênese, de forma a associar a lipólise ao "dia induzido" (ausência de melatonina no meio de cultura) e a lipogênese à "noite induzida" (presença de melatonina no meio de cultura). Da mesma maneira, a incubação rítmica dos adipócitos com melatonina provocou a sincronização dos clock genes desse tecido. Pode-se supor, portanto, que a regulação exercida pela melatonina sobre o metabolismo dos adipócitos pode estar sendo mediada pela regulação que ela exerce sobre a expressão dos clock genes, uma vez que a função desses genes é controlar a transcrição de outros genes denominados genericamente por "genes controlados pelo relógio".

No campo da interação insulina-melatonina, trabalhos na literatura estudaram os efeitos da pinealectomia e o papel da melatonina na secreção de insulina pelas células B de ilhotas pancreáticas isoladas. Delattre et al. (1999) demonstraram a modulação rítmica circadiana na capacidade de ilhotas pancreáticas isoladas de ratos secretarem insulina frente a uma estimulação glicêmica. Tecidos isolados imediatamente após o início de período de escuro tinham maior capacidade secretória frente ao mesmo estímulo pela glicose, indicando um processo rítmico adaptativo ao período de maior atividade e consumo alimentar pelos animais e também, que o tecido era capaz de manter, in vitro, a memória do horário de retirada. 
A hipótese de que a exposição diária à melatonina é que poderia ser a responsável por esse processo de sincronização funcional das ilhotas pancreáticas, levando-as a apresentarem um ritmo circadiano na resposta à glicose e de capacidade de secreção de insulina, necessária a adaptação desse sistema aos ciclos de alimentação e atividade e repouso dos animais, foi confirmada por Picinato et al. (2002a) que demonstraram que esse ajuste rítmico metabólico (capacidade secretória pancreática) está, de fato, na estrita dependência da presença diária de melatonina, uma vez que as ilhotas isoladas de animais pinealectomizados apresentam um adiantamento de fase da curva diária de secreção de insulina estimulada por glicose de quase 3 horas, fazendo com que seu pico de máxima responsividade caia durante o período de dia e não à noite quando seria mais adaptativo por ser o momento circadiano em que os animais se alimentam. Outros trabalhos mostram ainda que a melatonina tem um efeito inibitório agudo, dependente de PKA, sobre a secreção de insulina (PICINATO et al., 2002b), e que esses efeitos são mediados pelo receptor MT1, mobilizando as vias de sinalização da insulina e do IGF-1 (PICINATO et al., 2008).

Trabalhos que estudaram os mecanismos pelos quais a melatonina potencia a ação da insulina mostraram, tanto em tecidos periféricos quanto no sistema nervoso central, que essa indolamina induz diretamente fosforilação em resíduos tirosís, ativação da subunidade $\beta$ da tirosina quinase do receptor de insulina e fosforilação do IRS-1. Além disso, a melatonina induziu as associações IRS-1/PI3 quinase e IRS-1/SHP-2, além de fosforilação de AKT e de MAP quinases (ANHÊ et al., 2004; PICINATO et al., 2008).

A presença de receptores de insulina na glândula já foi demonstrada (HILL et al., 1986; KAR et al., 1993). Nosso grupo de trabalho, na tentativa de estudar alças regulatórias entre a produção de melatonina e os sinalizadores do metabolismo energético, demonstrou recentemente (GARCIA et al., 2008) que a insulina potencia a síntese de melatonina, estimulada pela noradrenalina na glândula pineal. Em culturas tradicionais a potenciação se deve a um aumento da atividade da triptofano hidroxilase. Por outro lado, em culturas sincronizadas pela adição de noradrenalina ritmicamente (12h sim e $12 \mathrm{~h}$ não) a insulina provoca uma alteração da atividade da AANAT sem alterar sua expressão.

\subsection{Melatonina e Diabetes}

Os primeiros registros na literatura analisando os efeitos do diabetes experimental sobre a síntese e secreção de melatonina mostraram, tanto em ratos quanto em hamsters (CHAMPNEY et al., 1983; PANG et al., 1985), que o diabetes quimicamente induzido por 
aloxana ou estreptozotocina provoca uma redução na síntese e nos níveis circulantes de melatonina. Essa diminuição na produção de melatonina pela glândula pineal seria principalmente resultante de uma redução da atividade da HIOMT. No entanto, há algumas contradições que precisaram ser melhor avaliadas. Assim, Champney et al., 1986 não viram efeito algum do diabetes induzido experimentalmente, bem como de injeções diárias de insulina, sobre o metabolismo pineal de ratos quanto aos níveis dos indóis e à atividade enzimática. Por outro lado, evidenciaram que no hamster a insulina aumenta a atividade da AANAT e não da HIOMT. No mesmo ano, O’Brien et al. (1986) mostraram que pacientes diabéticos com evidência de neuropatia autonômica não apresentam o aumento noturno fisiológico da melatonina plasmática, que encontra-se também alterado em pacientes sem neuropatia aparente, provavelmente caracterizando um estado subclínico de denervação simpática, de acordo com os autores.

Dados mais recentes também mostram certa controvérsia. Assim, Herichová et al. (2005) não encontraram diminuição na síntese pineal de melatonina em ratos Wistar após 7 dias de indução de diabetes com uma única dose de STZ (100mg/kg). O mesmo grupo mostrou, em contrapartida, diminuição da síntese pineal do referido indol, com níveis normais de melatonina plasmática, fator esse que merece atenção. Essa contradição com os dados anteriores foi explicada pelos autores como sendo relacionada ao desenvolvimento do quadro diabético. Os mesmos autores evidenciaram também níveis diminuídos no pâncreas, rins e duodeno, em animais diabéticos 17 dias pós-indução com estreptozotocina $(65 \mathrm{mg} / \mathrm{kg})$ (STEBELOVÁ et al., 2007).

Trabalho de Tutunco et al. (2005) mostrou que pacientes diabéticos com neuropatia autonômica cardíaca apresentaram níveis plasmáticos de melatonina diminuídos em relação à pacientes controles e a diabéticos sem neuropatia. Estudo em pacientes jovens adultos com síndrome metabólica não mostrou diferença nos níveis plasmáticos de melatonina, nem no perfil do referido indol, quando comparados a jovens adultos controles (ROBEVA et al., 2006).

Peschke et al. (2006) mostraram que ratos Goto Kakizaki espontaneamente diabéticos tipo 2 apresentam diminuição da síntese de melatonina e da atividade da AANAT, associada a níveis elevados tanto de glicemia quanto de insulinemia, quando comparados a ratos Wistar. O mesmo trabalho mostrou ainda que os níveis plasmáticos de melatonina em pacientes diabéticos tipo 2 estão diminuídos, em associação a níveis elevados de glicemia e a níveis não significativamente elevados de insulinemia. O mesmo grupo mostrou ainda (PESCHKE et al., 2008) aumento na melatonina plasmática de animais diabéticos tipo 1 tanto com 12 quanto 
com 51 semanas de idade, 6 semanas pós-indução com STZ. Além de também observarem aumento no RNAm da AANAT, do receptor de insulina e do receptor $\$ 1$-adrenérgico em animais de ambas idades, e aumento do RNAm para HIOMT nos animais de 12 semanas.

No campo da ação da melatonina no diabetes, encontramos dados variados na literatura mostrando que a melatonina reduziu a hiperglicemia e a hiperlipidemia em ratas diabéticas por STZ (MONTILLA et al., 1998); além de reduzir a hiperinsulinemia e a hiperlipidemia em ratos diabéticos Otsuka Long-Evans Tokushima Fatty (OLETF) (NISHIDA et al., 2002). Outros registros mostram que não houve diminuição da hiperglicemia em ratos diabéticos por STZ e posteriormente tratados intraperitonealmente com melatonina (VURAL et al., 2001), embora outro trabalho tenha mostrado que ratos diabéticos por estreptozotocina pré-tratados com melatonina apresentaram níveis hiperglicêmicos mais baixos do que os mesmos animais não-tratados (ABDEL-WAHAB e ABD-ALLAH, 2000).

Diante do exposto quanto à correlação funcional entre a melatonina e insulina e a heterogeneidade de dados sobre a síntese pineal do referido indol mediante o quadro de diabetes, fez-se premente a necessidade do estudo que originou a presente tese. 


\section{CONCLUSÕES}

Em resumo, os resultados encontrados mostraram que o diabetes quimicamente induzido por estreptozotocina causa diminuição na síntese pineal de melatonina, tanto 3 quanto 15 dias pós-indução e que perdura pelo menos até 18 dias pós-indução. Essa queda não é causada por necrose ou apoptose dos pinealócitos, e reflete um desarranjo no metabolismo pineal que se evidenciou mais claramente pela diminuição pronunciada na atividade da AANAT, resultando diretamente no importante decréscimo observado na síntese do referido indol. Essa redução apresentou-se acompanhada de um desbalanço rítmico de fatores determinantes para o processo, como a expressão do receptor $\beta 1$ e a atividade e expressão das enzimas TPH1 e HIOMT. Além disso, podem ter contribuído de forma importante para o quadro observado tanto a queda da produção de leptina quanto de insulina, intrínsecas ao quadro do diabetes induzido pela estreptozotocina.

Diante das evidências de prejuízo na síntese pineal de melatonina, do desbalanço rítmico presente em animais/pacientes diabéticos e de que o tratamento com esse mesmo hormônio melhora vários aspectos do quadro diabético, sugere-se que a diminuição na síntese de melatonina colabora para instalação e agravamento desse quadro, mostrando a necessidade de monitoramento desse parâmetro e possível reposição terapêutica para melhoria da qualidade de vida desses pacientes. 


\section{REFERÊNCIAS*}

ABDEL-WAHAB, M.H.; ABD-ALLAH, A.R.A. Possible protective effect of melatonin and/or desferrioxamine against streptozotocin-induced hyperglycaemia in mice. Pharmacol. Res., v. 41, n. 5, p. 533-537, 2000.

AKIRAV, E.M.; CHAN, O.; INOUYE, K.; RIDDELL, M.C.; MATTHEWS, S.G.; VRANIC, M. Partial Leptin Restoration Increases Hypothalamic-Pituitary-Adrenal Activity While Diminishing Weight Loss and Hyperphagia in Streptozotocin Diabetic Rats. Metabolism, v. 53, n. 12, p. 1558-1564, 2004.

AKSOY, N.; VURAL, H.; SABUNCU, T.; AKSOY, S. Effects of melatonin on oxidativeantoxidative status of tissues in streptozotocin-induced diabetic rats. Cell Biochem. Funct., v. 21, p. 121-125, 2003.

ALONSO-VALE, M.I.C.; ANHÊ, G.F.; BORGES-SILVA, C.N.; ANDREOTTI, S.; PERES, S.B.; CIPOLLA-NETO, J.; LIMA, F.B. Pinealectomy alters adipose tissue adaptability to fasting in rats. Metabolism, v. 53, p. 500-506, 2004a.

ALONSO-VALE, M.I.; BORGES-SILVA, C.N.; ANHÊ, G.F.; ANDREOTTI, S.; MACHADO, M.A.; CIPOLLA-NETO, J.; LIMA, F.B. Light/dark cycle-dependent metabolic changes in adipose tissue of pinealectomized rats. Horm. Metab. Res., v. 36, n. 7, p. 474479, 2004b.

ALONSO-VALE, M.I.; ANDREOTTI, S.; PERES, S.B.; ANHÊ, G.F.; DAS NEVES BORGES-SILVA, C.; NETO, J.C.; LIMA, F.B. Melatonin enhances leptin expression by rat adipocytes in the presence of insulin. Am. J. Physiol. Endocrinol. Metab., v. 288, n. 4, p. E805-812, 2005.

ALONSO-VALE, M.I.; ANDREOTTI, S.; BORGES-SILVA, C.N.; MUKAI, P.Y.; CIPOLLA-NETO, J.; LIMA, F.B. Intermittent and rhythmic exposure to melatonin in primary cultured adipocytes enhances the insulin and dexamethasone effects on leptin expression. $\mathbf{J}$. Pineal Res., v. 41, n. 1, p. 28-34, 2006.

ALONSO-VALE, M.I.; ANDREOTTI, S.; MUKAI, P.Y.; BORGES-SILVA, C.N.; PERES, S.B.; CIPOLLA-NETO, J.; LIMA, F.B. Melatonin and the circadian entrainment of metabolic and hormonal activities in primary isolated adipocytes. J. Pineal Res., v. 45, n. 4, p. 422-429, 2008 .

\footnotetext{
De acordo com: ASSOCIAÇÃO BRASILEIRA DE NORMAS TÉCNICAS. NBR 6023: Informação e documentação: referências: elaboração. Rio de Janeiro, 2002.
} 
AMARAL, F.G; COON, S. L.; KLEIN D.C. Significant sequence revision of rat acetylserotonin $\mathrm{O}$-methyltransferase mRNA increases length of predicted protein. Available from: $\quad<$ http://www.ncbi.nlm.nih.gov/entrez/viewer.fcgi?db=nuccore $\& i d=$ 189311138>. Acesso em: 05 Jan. 2009.

American Diabetes Association. Standards of Medical Care in Diabetes. Diabetes Care, v. 30, p. S4-S41, 2007. Suppl. 1.

ANDERSSON, A.K.; SANDLER, S. Melatonin protects against streptozotocin, but not interleukin-1beta-induced damage of rodent pancreatic beta-cells. J. Pineal Res., v. 30, n. 3, p. 157-165, 2001.

ANDO, H.; USHIJIMA, K.; YANAGIHARA, H.; HAYASHI, Y.; TAKAMURA, T.; KANEKO, S.; FUJIMURA, A. Clock gene expression in the liver and adipose tissues of nonobese type 2 diabetic Goto-Kakizaki rats. Clin. Exp. Hypertens., v. 31, n. 3, p. 201-207, 2009a.

ANDO, H.; TAKAMURA, T.; MATSUZAWA-NAGATA, N.; SHIMA, K.R.; ETO, T.; MISU, H.; SHIRAMOTO, M.; TSURU, T.; IRIE, S.; FUJIMURA, A.; KANEKO, S. Clock gene expression in peripheral leucocytes of patients with type 2 diabetes. Diabetologia, v. 52, p. 329-335, 2009b.

ANHÊ, G.F.; CAPERUTO, L.C.; PEREIRA-DA-SILVA, M.; SOUZA, L.C.; HIRATA, A.E.; VELLOSO, L.A.; CIPOLLA-NETO, J.; CARVALHO, C.R. In vivo activation of insulin receptor tyrosine kinase by melatonin in the rat hypothalamus. J. Neurochem., v. 90, n. 3, p. 559-566, 2004.

ANHOLT, R.R.H. Signal integration in the nervous system: adenylate cyclases as molecular coincidence detectors. TINS, v. 17, n. 1, p. 37-41, 1994.

ANWAR, M.M.; MEKI, A.M.A. Oxidative stress in streptozotocin-induced diabetic rats: effects of garlic oil and melatonin. Comp. Biochem. Physiol. Part A, v. 135, p. 539-547, 2003.

ARENDT, J. Melatonin and the Mammalian Pineal Gland. London: Chapman \& Hill, 1995.

BAEKKESKOV, S.; AANSTOOF, H.; CHRISTGAU, S., et al. Identification of the 64K autoantigen in insulin-dependent diabetes as the GABA-synthesizing enzyme glutamic acid decarboxilase. Nature, v. 347, p. 151, 1990. 
BAHOUTH, S.W.; CUI, X.; BEAUCHAMP, M.J. PARK, E.A. Thyroid hormone induces B1adrenergic receptor gene transcription through a direct repeat separated by five nucleotides. $\mathbf{J}$. Mol. Cell Cardiol., v. 29, p. 3223-3237, 1997.

BALTATU, O.; AFECHE, S.C.; SANTOS, S.H.J.; CAMPOS, L.A.; BARBOSA, R.; MICHELINI, L.C.; BADER, M.; CIPOLLA-NETO, J. Locally synthesized angiotensin modulates pineal melatonin generation. J. Neurochem., v. 80, p. 328- 334, 2002.

BALER, R.; KLEIN, D.C. Circadian expression of transcription factor Fra-2 in the rat pineal gland. J. Biol. Chem., v. 270, p. 27319-27325, 1995.

BALER, R.; COVINGTON, S.; KLEIN, D.C. The rat arylalkylamine $N$-acetyltransferase gene promoter - cAMP activation via a cAMP-responsive element-CCAAT complex. J. Biol. Chem., v. 272, n. 11, p. 6979-6985, 1997.

BANIK, U.; WANG, G.A.; WAGNER, P.D.; KAUFMAN, S. Interaction of phosphorylated tryptophan hydroxylase with 14-3-3 proteins. J. Biol. Chem., v. 272, p. 26219-26225, 1997.

BARCELÓ, A.; AEDO, C.; RAJPATHAK, S.; ROBLES, S. The cost of diabetes in Latin America and the Caribean. Bull. World Health Organ, v. 81, n. 1, p. 19-27, 2003.

BARRETT, P.; MacLEAN, A.; DAVIDSON, G.; MORGAN, P.J. Regulation of the Mel 1a melatonin receptor mRNA and protein levels in the ovine pars tuberalis: Evidence for a cyclic adenosine 3',5'-monophosphate-independent Mel 1a receptor coupling and an autoregulatory mechanism expression. Mol. Endocrinol., v. 10, p. 892-902, 1996.

BAYDAS, G.; CANATAN, H.; TURKOGLU, A. Comparative analysis of the protective effects of melatonin and vitamin E on streptozocin-induced diabetes mellitus. J. Pineal Res., v. 32, p. 225-30, 2002.

BAYDAS, G.; REITER, R.J.; YASAR, A.; TUZCU, M.; AKDEMIR, I.; NEDZVETSKII, V.S. Melatonin reduces glial reactivity in the hippocampus, cortex, and cerebellum of streptozotocin-induced diabetic rats. Free Radic. Biol. Med., v. 35, n. 7, p. 797-804, 2003.

BEDOYA, F.J.; SOLANO, F.; LUCAS, M. N-monomethul-arginine and apoptosis prevent streptozotocin-induced double strand DNA break formation in pancreatic rat islets. Experimentia, v. 52, p. 344-347, 1996. 
BESANÇON, R.; SIMONNEAUX, V.; JOUVET, A.; BELIN, M.F.; FÈVRE-MONTANGE, M. Nycthmeral expression of tryptophan hydroxylase mRNAs in the rat pineal gland. Mol. Brain Res., v. 40, p. 136-8, 1996.

BOADLE-BIBER, M.C. Activation of tryptophan hydroxylase from slices of rat brain stem incubated with $\mathrm{N}^{6}, \mathrm{O}^{2}$-dibutyryl adenosine-3':5'-cyclic monophosphate. Biochem. Pharmacol., v. 29, p. 669-72, 1980.

BORGES-SILVA， C.N.; ALONSO-VALE， M.I.; FRANZÓI-DE-MORAES， S.M.; TAKADA, J.; PERES, S.B.; ANDREOTTI, S.; SKORUPA, A.L.; CIPOLLA-NETO, J.; PITHON-CURI, T.C.; LIMA, F.B. Pinealectomy impairs adipose tissue adaptability to exercise in rats. J. Pineal Res., v. 39, n. 2, p. 178-84, 2005 a.

BORGES-SILVA, C.N.; FONSECA-ALANIZ, M.H.; ALONSO-VALE, M.I.; TAKADA, J.; ANDREOTTI, S.; PERES, S.B.; CIPOLLA-NETO, J.; PITHON-CURI, T.C.; LIMA, F.B. Reduced lipolysis and increased lipogenesis in adipose tissue from pinealectomized rats adapted to training. J. Pineal Res., v. 39, n. 2, p. 178-84, 2005 b.

BORGES-SILVA, C.N.; TAKADA, J.; ALONSO-VALE, M.I.; PERES, S.B.; FONSECAALANIZ, M.H.; ANDREOTTI, S.; CIPOLLA-NETO, J.; PITHON-CURI, T.C.; LIMA, F.B. Pinealectomy reduces hepatic and muscular glycogen content and attenuates aerobic power adaptability in trained rats. J. Pineal Res., v. 43, n. 1, p. 96-103, 2007.

BORJIGIN, J.; WANG, M.M.; SNYDER, S.H. Diurnal variation in mRNA encoding serotonin N-acetyltransferase in pineal gland. Nature, v. 378, p. 783-785, 1995.

BOUATIA-NAJI, N.; BONNEFOND, A.; CAVALCANTI-PROENÇA, C.; SPARSO, T.; HOLMKVIST, J. et al. A variant near MTNR1B is associated with increased fasting plasma glucose levels and type 2 diabetes risk. Nat. Genet., v. 41, n. 1, p. 89- 94, 2009.

BOULARAND, S.; DARMON, M. C.; RAVASSARD, P.; MALLET, J. Characterization of the human tryptophan hydroxylase gene promoter. Transcriptional regulation by cAMP requires a new motif distinct from the cAMP-responsive element. J. Biol. Chem., v. 270, p. 3757-3764, 1995.

BURKE, Z.; WELLS, T.; CARTER, D.; KLEIN, D.; BALER, R. Genetic targeting: the serotonin $N$-acetyltransferase promoter imparts circadian expression selectively in the pineal gland and retina of transgenic rats. J. Neurochem., v. 73, p.1343-1349, 1999. 
CAM, M.; YAVUZ, O.; GUVEN, A.; ERCAN, F.; BUKAN, N.; ÜSTUNDAG, N. Protective effects of chronic melatonin treatment against renal injury in streptozotocin-induced diabetic rats. J. Pineal Res., v. 35, p. 212-220, 2003.

CARDINALI, D.P.; LYNCH, H.J.; WURTMAN, R.J. Binding of melatonin to human and rat plasma proteins. Endocrinology, v. 91, p. 1213-1218, 1972.

CARDINALI, D.P.; VACAS, M.I. Cellular and molecular mechanisms controlling melatonin release by mammalian pineal glands. Cell Mol. Neurobiol., v. 7, p. 323-337, 1987.

CARLBERG, C.; WIESENBERG, I. The orphan receptors family RZR/ROR, melatonin and 5-lipoxygenase: An unexpected relationship. J. Pineal Res., v. 18, p. 171-178, 1995.

CARTER, D.A. Up-regulation of beta 1-adrenoceptor messenger ribonucleic acid in the rat pineal gland: nocturnally, through a beta-adrenoceptor-linked mechanism, and in vitro, through a novel posttranscriptional mechanism activated by specific protein synthesis inhibitors. Endocrinology, v. 133, p. 2263-2268, 1993.

CHAMPNEY, T.H.; BRAINARD, G.C.; RICHARDSON, B.A.; REITER, R.J. Experimentally-induced diabetes reduces nocturnal pineal melatonin content in the Syrian hamster. Comp. Biochem. Physiol., v. 76, p. 199-201, 1983.

CHAMPNEY, T.H.; HOLTORF, A.P.; CRAFT, C.M.; REITER, R.J. Hormonal modulation of pineal melatonin synthesis in rats and Syrian hamsters: effects of streptozotocin-induced diabetes and insulin injections. Comp. Biochem. Physiol., v. 83, p. 391-395, 1986.

CHIK, C.L.; LI, B.; KARPINSKI, E.; HO, A.K. Insulin and insulin-like growth factor-I inhibit the L-type calcium channel current in rat pinealocytes. Endocrionology, v. 138, n. 5, p. 2033-2042, 1997.

CHICK, C.L.; ARNASON, T.G.; DUKEWICH, W.G.; PRICE, D.M.; RANGER, A.; HO, A.K. Histone $\mathrm{H} 3$ phosphorylation in the rat pineal gland: adrenergic regulation and diurnal variation. Endocrinology, v. 148, p. 1465-1472, 2007.

CHRISTOY, B.; KROMANN, H. Incidence seasonal and geographical patterns of juvenileonset-insulin dependent diabetes mellitus in Denmark. Diabetologia, v. 13, p. 281, 1977. 
CIPOLLA-NETO, J.; SKORUPA, A.L.; RIBEIRO-BARBOSA, E.R.; BARTOL, I.; MOTA, S.R.; AFECHE, S.C.; DELAGRANGE, P.; GUARDIOLA-LEMAITRE, B.; CANTERAS, N.S. The role of the retrochiasmatic area in the control of pineal metabolism. Neuroendocrinology, v. 69 , n. 2, p. 97-104, 1999.

CIPOLLA-NETO, J.; AFECHE, S.C. Glândula Pineal. In: AIRES, M.M (Ed.). Fisiologia. 3. ed. Rio de Janeiro: Guanabara-Koogan, 2008. p. 981-990.

COLLIN, J.P. Contribution A`L'e'Tude De L'organe Pine'Al. De L'e'Piphyse Sensorielle A` La Glande Pine'Ale : Modalite'S De Transformation Et Implications Fonctionelles. Ann. Stn Biol. $=$ Besse-En-Chandesse, p. 1-359, 1969. Suppl. 1.

COLLIN, J.P. Differentiation and regression of the cells of the sensory line in the epiphysis cerebri. In: WOLSTENHOLME, G.E.W.; KNIGHT, J. The Pineal Gland. London: J. A. Churchill, 1971. p. 79-125.

COLLINS, S.; OSTROWSKI, J.; LEFKOWITZ, R.J. Cloning and sequence analysis of the human $\beta 1$-adrenergic receptor 5'-flanking promoter region. Biochem. Biophys. Acta, v. 1172, p. 171-174, 1993.

CONTRERAS, J.L.; SMYTH, C.A.; CURIEL, D.T.; ECKHOFF, D.E. Nonhuman primate models in type 1 diabetes research. Ilar J., v. 45, n. 3, p. 334-342, 2004.

COON, S.L.; MCCUNE, S.K.; SUGDEN, D.; KLEIN, D.C. Regulation of pineal $\alpha 1 \mathrm{~B}-$ adrenergic receptor mRNA: day/night rhythm and $\beta$-adrenergic receptor/cyclic AMP control. Mol. Pharmacol., v. 51, p. 551-557, 1997.

COON, S.L.; WELLER, J.L.; KORF, H.W.; NAMBOODIRI, M.A.; ROLLAG, M.; KLEIN, D.C. cAmp regulation of arylalkylamine N-acetyltransferase (AANAT, EC 2.3.1.87): a new cell line (1E7) provides evidence of intracellular AANAT activation. J. Biol. Chem., v. 276, n. 26, p. 24097-24107, 2001.

CÔTÉ F.; SCHUSSLER, N.; BOULAR, S.; PEIROTES, A.;THEVE, E.; MALLET J.; VODJDANI, G. Involvement of NF-Y and Sp1 in basal and cAMP stimulated transcriptional activation of the tryptophan hydroxylase (TPH) gene in the pineal gland. J. Neurochem., v. 81, p. 673-685, 2002.

CRANDALL, E.A.; GILLIS, M.A.; FERNSTROM, J.D. Reduction in brain serotonin synthesis rate in streptozotocin-diabetic rats. Endocrinology, v. 109, n.1, p. 310-312, 1981. 
DEGUCHI, T.; AXELROD, J. Sensitive assay for serotonin N-acetyltransferase activity in rat pineal. Anal. Biochem., v. 50, p. 176-179, 1972.

DELATTRE, E.; CIPOLlA-NETO, J.; BOSCHERO, A.C. Diurnal variations in insulin secretion and $\mathrm{K}^{+}$permeability in isolated rat islets. Clin. Exper. Pharmacol. Physiol., p. 505$510,1999$.

DELFINO, V.D.A.; FIGUEIREDO, J.F.; MATSUO, T.; FAVERO, M.A.; MATNI, A.M.; MOCELIN, A.J. Diabetes melittus induzido por estreptozotocina: comparação em longo prazo entre duas vias de administração. J. Bras. Nefrol., v. 24, n. 1, p. 31-36, 2002.

DOUGLAS, C.R. Tratado de Fisiologia Aplicada às Ciências da Saúde. 4.ed. São Paulo: Robe Editorial. 1999. p. 1090-1093.

DRIJFHOUT, W. J.; GROL, C. J.; WESTERINK, B. H. C. Microdialysis of melatonin in the rat pineal gland: methodology and pharmacological applications. J. Neurochem., v. 61, p. 936-942, 1993.

DUBOCOVICH, M.L. Melatonin receptors: are there multiple subtypes? Trends Pharmacol. Sci., v. 16, p. 50-56, 1995.

EHRET, M.; CASH, C.D.; HAMON, M.; MAITRE, M. Formal demonstration of the phosphorilation of rat brain tryptophan hydroxylase by $\mathrm{Ca}^{2+} /$ calmodulin-dependent protein kinase. J. Neurochem., v. 52, p. 1886-1891, 1989.

EHRET, M.; PEVET, P.; MAITRE, M. Tryptophan hydroxylase synthesis is induced by 3',5'cyclic adenosine monophosphate during circadian rhythm in the rat pineal gland. $\mathbf{J}$. Neurochem., v. 57, p. 1516-1521, 1991.

EKSTROM, P.; MEISSL, H. Evolution of photosensory pineal organs in new light: the fate of neuroendocrine photoreceptors. Philos. Trans. R. Soc. Lond. B. Biol. Sci., v. 358, n. 1438, p. 1679-1700, 2003.

FRASER, S.; COWEN, P.; FRANKLIN, M.; FRANEY, C.; ARENDT, J. Direct radioimmunoassay for melatonin in plasma. Clin. Chem., v. 29, p. 396-7, 1983.

FRAZER, A.; HENSLER, J.G. Serotonin. In: SIEGEL, G.J. et al. (Ed.). Basic neurochemistry: molecular, cellular and medical aspects. New York: Raven Press, 1994. p. 283-308. 
FURUKAWA, Y.; IKUTA, N.; OMATA, S.; YAMAUCHI, T.; ISOBE, T.; ICHIMURA, T. Demonstration of the phosphorylation-dependent interaction of tryptophan hydroxylase with the 14-3-3 protein. Biochem. Biophys. Res. Commun., v. 194, p. 144-149, 1993.

GANGULY, S.; GASTEL, J.A.; WELLER, J.L.; SCHWARTZ. C.; JAFFE. H.; NAMBOODIRI, M.A.A.; COON, S.L.; HICKMAN, A.B.; ROLLAG, M.; OBSIL, T.; BEAUVERGER, P.; FERRY, G.; BOUTIN, J.A.; KLEIN, D.C. Role of a pineal cAMPoperated arylalkylamine N-acetyltransferase/ 14-3-3-binding switch in melatonin synthesis. Proc. Natl. Acad. Sci., v. 98, p. 8083-8088, 2001.

GANGULY, S.; WELlER, J.L.; HO, A.; CHEMINEAU, P.; MALPAUX, B.; KLEIN, D.C. Melatonin synthesis: 14-3-3-dependent activation and inhibition of arylalkylamine $\mathrm{N}$ acetyltransferase mediated by phosphoserine-205. Proc. Natl. Acad. Sci., v. 102, p. 12221227, 2005.

GARCIA, R.A.P.; AFECHE, S.C.; SCIALFA, J.H.; AMARAL, F.G.; SANTOS, S.H.J.; LIMA, F.B.; YOUNG, M.E.; CIPOLLA-NETO, J. Insulin modulates norepinephrinemediated melatonin synthesis in cultured rat pineal gland. Life Sci., v. 82, p.108-114, 2008.

GARIDOU, M.L.; BARTOL, I.; CALGARI, C.; PÉVET, P.; SIMONNEAUX, V. In vivo observation of a non-noradrenergic regulation of arylakylamine $\mathrm{N}$-acetiltransferase gene expression in the pineal complex. Neuroscience, v. 105, p. 721-729, 2001.

GASTEL, J.A; ROSEBOOM, P.H.; RINALDI, P.A.; WELLER, J.L.; KLEIN, D.C. Melatonin production: proteasomal proteolysis in serotonin $\mathrm{N}$-acetyltransferase regulation. Science, v. 279, p. 1358-1360, 1998.

GAUER, F.; CRAFT, C.M. Circadian regulation of hydroxyindole-Omethyltransferase mRNA levels in rat pineal and retina. Brain Res., v. 737, p. 99-109, 1996.

GILLE, L.; SCHOTT-OHLY, P.; FRIESEN, N. et al.. Generation of hydroxyl radicals mediated by streptozotocin in pancreatic islets of mice in vitro. Pharmacol. Toxicol., v. 90, p. 317-326, 2002.

GOMPERTS, B.D.; KRAMER, I.M.; TATHAM, P.E.R. Signal transduction. San Diego: Academic Press, 2002. p. 145-187.

GORGUN, F.M.; OZTURK, Z.; GUMUSTAS, M.K., KOKOGU, E. Melatonin administration affects plasma total sialic acid and lipid peroxidation levels in streptozotocin induced diabetic rats. J. Toxicol. Environ. Health, v. 24, n. 65, p. 695-700, 2002. 
GUVEN, A.; YAVUZ, O.; CAM, M.; ERCAN, F.; BUKAN, N.; COMUNOGLU, C.; GOKCE, F. Effects of melatonin on streptozotocin-induced diabetic liver injury in rats. Acta Histochem., v. 108, n. 2, p. 85-93, 2006.

HADCOCK, J.R.; MALBON, C.C. Regulation of $ß$-adrenergic receptors by "permissive"hormones: glucocorticoids increase steady-state levels of receptor mRNA. Proc. Natl. Acad. Sci., v. 85, p.8415-8419, 1988.

HAMON, M.; BOURGOIN, S.; HERY, F.; SIMONNET, G. Phospholipid-induced activation of tryptophan hydroxylase from rat brain stem. Biochem. Pharmacol., v. 27, p. 915-22, 1978.

HAVEL, P.J.; URIU-HARE, J.Y.; LIU, T.; STANHOPE, K.L.; STERN, J.S.; KEEN, C.L.; AHRÉN, B. Marked and rapid decreases of circulating leptin in streptozotocin diabetic rats: reversal by insulin. Am. J. Physiol. Regul. Integr. Comp. Physiol., v. 274, p. 1482-1491, 1998

HERICHOVÁ, I.; ZEMAN, M.; STEBELOVÁ, K.; RAVINGEROVÁ, T. Effect of streptozotocin-induced diabetes on daily expression of per2 and dbp in the heart and liver and melatonin rhythm in the pineal gland of Wistar rat. Mol. Cell. Biochem., v. 270, p. 223-229, 2005.

HERR, R.R.; JAHNKE, A.D.; ARGOUDELIS, A.D. The structure of streptozotocin, a new antibacterial antibiotic. Antibiot. Ann., v. 7, p. 230-235, 1959/1960.

HERRERA, R.; MANJARREZ, G.; NISHIMURA, E.; HERNANDEZ, J. Serotonin-related tryptophan in children with insulin dependent diabetes. Pediatr. Neurol., v. 28, p. 20-23, 2003.

HILL, J.M.; LESNIAK, M.A.; PERT, C.B.; ROTH, J. Autoradiographic localization of insulin receptors in rat brain: prominence in olfactory and limbic areas. Neuroscience, v. 17, n. 4, p. 1127-1138, 1986.

HUANG, Z.; LIU, T.; CHATTORAJ, A.; AHMED, S.; WANG, M.M.; DENG, J.; SUN, X.; BORJIGIN, J. Posttranslational regulation of TPH1 is responsible for the nightly surge of 5HT output in the rat pineal gland. J. Pineal Res., v. 45, p. 506-514, 2008.

HUETHER, G.; POEGGLER, B.; RETMER, A.; GEORGE, A. Effect of tryptophan administration on circulating melatonin levels in chicks and rats: evidence for stimulation of melatonin synthesis and release in the gastrointestinal tract. Life Sci., v. 51, n. 12, p. 945-953, 1992. 
ICHIMURA, T.; ISOBE, T.; OKUYAMA, T.; YAMAUCHI, T.; FUJISAWA, H. Brain 14-33 protein is an activator protein that activates tryptophan 5-monooxygenase in the presence of Ca2+, calmodulin-dependent protein kinase II. FEBS Lett., v. 219, p. 79-82, 1987.

IMAI, Y.; YAMAUCHI, T.; FUJISAWA, H. Modulation of tryptophan hydroxylase activity by phospholipids: stimulation followed by inactivation. J. Neurochem., v. 53, p. 1293-1299, 1989.

INTERNATIONAL DIABETES FEDERATION. Diabetes Atlas. 3. ed. Available from: $<$ http://www.eatlas.idf.org/atlasff5d.html?id=0>. Acesso em: 30 May 2009.

INTERNATIONAL DIABETES FEDERATION. What is Diabetes?. Available from: <http://www.idf.org/node/1049? unode=3B96844A-C026-2FD3-87E85FD2293F42E9>.

Acesso em: 30 May 2009.

JOHANSEN, P.A.; JENNINGS, I.; COTTON, R.G.H.; KUHN, D.M. Tryptophan hydroxylase is phosphorylated by protein kinase A. J. Neurochem., v. 65, p. 882-888, 1995.

JUNOD, A.; LAMBERT, A.E.; ORCI, L.; GONET, A.E.; RENOLD, A.E. Studies on the diabetogenic action of streptozotocin. Proc. Soc. Exp. Biol. Med., v. 126, p. 201-205, 1967.

JUNOD, A.; LAMBERT, A.E.; STAUFFACHER, W.; RENOLD, A.E. Diabetogenic action of streptozotocin: relationship of dose to metabolic response. J. Clin. Invest., v. 48, p. 21292139, 1969.

KANTER, M., UYSAL, H., KARACA, T., SAGMANLIGIL, H.O. Depression of glucose levels and partial restoration of pancreatic beta-cell damage by melatonin in streptozotocin-induced diabetic rats. Arch. Toxicol., v. 80, n. 6, p. 362-369, 2006.

KAR, S.; CHABOT, J.G.; QUIRION, R. Quantitative autoradiographic localization of $\left[{ }^{125} \mathrm{I}\right]$ Insulin-like growth factor I, $\left[{ }^{125} \mathrm{I}\right]$ Insulin-like growth factor Ii, and [ $\left.{ }^{125} \mathrm{I}\right]$ Insulin receptor binding sites in developing and adult rat brain. J. Comp. Neurol., v. 333, p. 375-397, 1993.

KATSUMATA, K.; KATSUMATA, K. Jr; KATSUMATA, Y. Protective effect of diltiazem hydrochloride on the occurrence of alloxan or streptozotocin-induced diabetes in rats. Horm. Metab. Res., v. 24, p. 508-510, 1992.

KEBABIAN, J.W.; ZATZ, M.; ROMERO, J.A.; AXELROD, J. Rapid changes in rat pineal 3 -adrenergic receptor: Alterations in 1-[3H]alprenolol binding and adenylate cyclase. Proc. Nat. Acad. Sci., v. 72, n. 9, p. 3735-3739, 1975. 
KIRIGITI, P.; BAI, Y.; YANG, Y-F.; LI, X.; LI, B.; BREWER, G.; MACHIDA, C.A. Agonist-mediated down-regulation of rat B1-adrenergic receptor transcripts: role of potential post-transcriptional degradation factors. Mol. Pharmacol., v. 60, n. 6, p. 1308-1324, 2001.

KLEIN, D.C.; BERG, G.R.; WELLER, J. Melatonin synthesis: adenosine 3',5'monophosphate and norepinephrine stimulate N-acetyltransferase. Science, v. 168, n. 934, p. 979-980, 1970.

KLEIN, D.C.; WELLER, J.L. Indole metabolism in the pineal gland: a circadian rhythm in Nacetyltransferase. Science, v. 169, n. 950, p. 1093-1095, 1970.

KLEIN, D.C.; WELLER, J.L.; MOORE, R.Y. Melatonin metabolism: neural regulation of pineal serotonin: acetyl coenzyme A N-acetyltransferase activity. Proc. Nat. Acad. Sci., v. 68, n. 12, p. 3107-3110, 1971.

KLEIN, D.C.; WELLER, J.L. Rapid Light-Induced Decrease In Pineal Serotonin NAcetyltransferase Activity. Science, v. 177, p. 532-533, 1972.

KLEIN, D.C.; BUDA, M.J.; KAPOOR, C.L.; KRISHNA, G. Pineal serotonin Nacetyltransferase activity: abrupt decrease in adenosine 3,5'-monophosphate may be signal for “Turnoff”. Science, v. 199, p. 309-311, 1978.

KLEIN, D.C.; AUERBACH, D.A.; NAMBOODIRI, M.A.A.; WELLER, G.H.T. Indole metabolism in the mammalian pineal gland. In: REITER, R.J. (Ed.). The Pineal Gland. Boca Raton: CRC Press, 1981.

KLEIN, D.C.; SUGDEN, D.; WELLER, J.L. Postsynaptic $\alpha$-adrenergic receptors potentiate the $\beta$-adrenergic stimulation of pineal serotonin $\mathrm{N}$-acetyltransferase. Proc. Natl. Acad. Sci. USA, v. 80, p. 599-603, 1983.

KLEIN, D. C. Photoneural regulation of the mammalian pineal gland. In: Photoperiodism, Melatonin and the Pineal. Ciba Foundation Symposium 117. Londres: Pitman, 1985. p. 38-56.

KLEIN, D.C.; SCHAAD, N.L.; NAMBOODIRI, M.A.A.; YU, L.; WELLER, J.L. Regulation of pineal serotonin N-acetyltransferase activity. Biochem. Soc. Trans., v. 20, n. 2, p. 299304, 1992.

KLEIN, D.C.; ROSEBOOM, P.H.; COON, S.L. New light is shining on the melatonin rhythm enzyme. The first poscloning view. TEM, v. 7, p. 106-112, 1996. 
KLEIN, D.C.; COON, S.L.; ROSEBOOM, P.H.; WELLER, J.L.; BERNARD, M.; GASTEL, J.A.; ZATZ, M.; IUVONE, P.M.; RODRIGUEZ, I.R.; BÉGAY, V.; FALCÓN, J.; CAHILL, G.M.; CASSONE, V.M.; BALER, R. The melatonin rhythm-generating enzyme: molecular regulation of serotonin $\mathrm{N}$-acetyltransferase in the pineal gland. Recent Prog. Horm. Res., v. 52, p. 307-358, 1997.

KLEIN, D.C.; GANGULY, S.; COON, S.; WELLER, J.L.; OBSIL, T.; HICKMAN, A.; DYDA, F. 14-3-3 Proteins and photoneuroendocrine transduction: role in controlling the daily rhythm in melatonin. Biochem. Soc. Trans., v. 30, p. 365-373, 2002.

KLEIN, D.C.; GANGULY, S.; COON, S.Q.; GAILDRAT, P.; MORIN, M.; WELLER, J.L.; OBSIL, T. 14-3-3 proteins in pineal photoneuroendocrine transduction: how many roles? J. Neuroendocrinol., v. 15, p. 370-7, 2003.

KLEIN, D.C. The pineal gene expression party: Who's the surprise guest? Endocrinology, v. 148, n. 4, p. 1463-1464, 2007.

KOCH, M.; MAUHIN, V.; STEHLE, J.H.; SCHOMERUS, C.; KORF, H.W. Desphosphorylation of pCREB by protein serine/threonine phosphatase is involved in inactivation of NAT gene transcription in rat pineal gland. J. Neurochem., v. 85, p. 170-179, 2003.

KONRAD, R.J.; MIKOLAENKO, I.; TOLAR, J.F.; LIU, K.; KUDLOW, J.E. The potential mechanism of the diabetogenic action of streptozotocin: inhibition of pancreatic $B$-cell $\mathrm{O}$ GlcNac-selective N-acetyl-ß-D-glucosaminidase. Biochem. J., v. 356, p. 31-41, 2001.

KORF, H.W. Evolution of melatonin-producing pinealocytes. In: OLCESE, J. Melatonin After Four Decades. New York: Kluwer/Plenum. 2000. p. 17-29.

KRÖNCKE, K.D.; FEHSEL, K.; SOMMER, A.; RODRIGUEZ, M.L.; KOLB-BACHFEN, V. Nitric oxide generation during cellular metabolization of diabetogenic streptozotocin contributes to islet cell DNA damage. Bio. Chem. Hoppe-Seyler, v. 376, p. 179-185, 1995.

KUHN, D.M.; VOGEL, R.L.; LOVENBERG, W. Calcium-dependent activation of tryptophan hydroxylase by ATP and magnesium. Biochem. Biophys. Res. Commun., v. 82, p. 759-766, 1978.

LI, X.; CHEN, S.; WANG, Q.; ZACK, D.J.; SNYDER, S.H.; BORJIGIN, J. A pineal regulatory element (PIRE) mediates transactivation by the pineal/retina specific transcription factor CRX. Proc. Natl. Acad. Sci., v. 95, p. 1876-1881, 1998. 
la FLEUR, S.E.; KALSBEEK, A.; WORTEL, J.; BUIJIS, R.M. A suprachiasmatic nucleus generated rhythm in basal glucose concentrations. J. Neuroendocrinol., v. 11, p. 643-652, 1999.

LACKOVIC, Z.; SALKOVIC, M. Streptozotocin and alloxan produce alterations in rat brain monoamines independently of pancreatic beta cells destruction. Life Sci., v. 46, p. 49-54, 1990.

LANGENBERG, C.; PASCOE, L.; MARI, A.; TURA, A.; LAAKSO, M.; FRAYLING, T. M.; BARROSO, I.; LOOS, R.J.F.; WAREHAM, N.J.; WALKER, M. Common genetic variation in the melatonin receptor 1B gene (MTNR1B) is associated with decreased earlyphase insulin response. Diabetologia, v. 52, n. 8, p. 1537-1542, 2009.

LENZEN, S. The mechanisms of alloxan- and streptozotocin-induced diabetes. Diabetologia, v. 51, p. 216-226, 2008.

LERCHL, A.; NONAKA, K.; STOKKAN, K.A.; REITER, R.J. Rapid alterations in nocturnal pineal serotonin in mice and rats exposed to weak intermittent magnetic fields. Biochem. Biophys. Res. Commun., v. 169, p. 102-108, 1990.

LERNER, A.B. et al. Isolation of melatonin, the pineal gland factor that lightens melanocytes. J. Am. Chem. Soc., v. 80, p. 2587, 1958.

LEWIS, C.; BARBIERS, A.R. Streptozotocin, a new antibiotic. In vitro and in vivo evaluation. Antibiot. Ann., v. 7, p. 247-254, 1970.

LIMA, F.B.; MATSUSHITA, D.H.; HELL, N.S.; DOLNIKOFF, M.S.; OKAMOTO, M.M.; CIPOLLA- NETO, J. The regulation of insulin action in isolated adipocytes. Role of the periodicity of food intake, time of the day and melatonin. Braz. J. Med. Biol. Res., p.9951000, 1994.

LIMA, F.B.; MACHADO, U.F.; BARTOL, I.; SERAPHIM, P.M.; SUMIDA, D.H.; MORAES, S.M.F.; HELL, N.S.; OKAMOTO, M.N.O.; SAAD, M.J.; CARVALHO, C.R.O.; CIPOLLA-NETO, J. Pinealectomy causes glucose intolerance and decreases adipose cell responsiveness to insulin in rats. Am. J. Physiol., v. 275, p. E934- E941, 1998. (Endocrinol. Metab., 38).

MALERBI, D.A.; FRANCO, L.J., em nome do Comitê Assessor para o Estudo da Prevalência de Diabetes no Brasil. Multicenter Study of the Prevalence of Diabetes Mellitus and Impaired Glucose Tolerance in the Urban Brazilian Population Aged 30-69 Yr. Diabetes Care, v. 15, n. 11, p. 1509-1516, 1992. 
MARONDE, E.E.; WICHT, H.; TASKÉN, K.; GENIESSER, H.G.; DEGHANI, F.; OLCESE, J.; KOLF, H.W. CREB phosphorylation and melatonin biosynthesis in the rat pineal: involvement of cyclic AMP dependent protein kinase Type II. J. Pineal Res., v. 27, p. 170-182, 1999.

MARTINS, E.Jr.; FERNANDES, L.C.; BARTOL, I.; CIPOLLA-NETO, J.; ROSA, L.F. The effect of melatonin chronic treatment upon macrophage and lymphocyte metabolism and function in Walker-256 tumour-bearing rats. J. Neuroimmunol., p. 81-89, 1998.

MAYO, J.C.; SAINZ, R.M.; URIA, H. et al Melatonin prevents apoptosis induced by 6 hydroxydopamine in neuronal cells: implications for Parkinson disease. J. Pineal Res., v.24, p. 179-192, 1998.

McKINNEY, J.; KNAPPSKOG, P.M.; HAAVIK, J. Different properties of the central and peripheral forms of human tryptophan hydroxylase. J. Neurochem., v. 92, p. 311-320, 2005.

McLEOD, S.D.; CAIRNCROSS, K.D. Preliminary evidence of a synergistic $\alpha 1-$ and B1adrenoceptor regulation of rat pineal hydroxyindole-O-methyltransferase. Gen. Comp. Endocrinol., v. 97, p. 283-288, 1995.

MEFFORD, I.N.; CHANG, P.; KLEIN, D.C.; NAMBOODIRI, M.A.A.; SUGDEN, D.; BARCHAS, J. Reciprocal day/night relationships between serotonin oxidation and $\mathrm{N}$ acetylation products in the rat pineal gland. Endocrinology, v. 113, n. 5, p. 1582-1586, 1983.

MOLLER, M.; PHANSUWAN-PUJITO, P.; MORGAN, K.C.; BADIN, C. Localization and diurnal expression on mRNA encoding the beta1-adrenoceptor in the rat pineal gland: an in situ hybridization study. Cell Tissue Res., v. 288, p. 279-284, 1997.

MONTILLA, P. L.; VARGAS, J. F.; TÚNEZ, I. F.; de AGUEDA, M. C. M.; VALDELVIRA, M. E. D.; CABRERA, E. S. Oxidative stress in diabetic rats induced by streptozotocin: protective effects of melatonin. J. Pineal Res., v. 25, p. 94-100, 1998.

MORGAN, C.R.; LAZAROW, A. Immunoassay of insulin: two antibodies system: plasma insulin levels of normal, subdiabetic and diabetic rats. Diabetes, v.12, p.115-121, 1963.

MORGAN, P.; BARRET, P.; HOWELL, H.; HELLIWEL, R. Melatonin receptors: localization, molecular pharmacology and physiological significance. Neurochem. Int., v. 24, p. 101-146, 1994. 
MULDER, H.; NAGORNY, C.L.; LYSSENKO, V.; GROOP, L. Melatonin receptors in pancreatic islets: good morning to a novel type 2 diabetes gene. Diabetologia, v. 52, n. 7, p. 1240-1249, 2009.

MÜLLER, D.; NITSCH, R.M.; WURTMAN, R.J.; HOYER S. Streptozotocin increases free fatty acids and decreases phospholipids in rat brain. J. Neural Transm., v. 105, p. 1271$1281,1998$.

NERUP, J.; CHRISTY, M.; PLATZ, P.; RYDER, L.P; SVEJGAARD, A. Aspects of the genetics of insulin dependent diabetes mellitus. In: ANDREANI, D.; DiMARIO, U.; FEDERLIN, K.F.; HEDING, L.G. Immunology in Diabetes. London: Kimpton Medic. Publication, 1984. p. 63.

NICOLETTI, I.; MIGLIORATI, G.; PAGLIACCI, M.C.; GRIGNANI, F.; RICCARDI, C. A rapid and simple method for measuring thymocytes apoptoses by propidium iodide staining and flow cytometry. J. Immunol. Methods, v. 123, p. 271-279, 1991.

NISHIDA, S.; SEGAWA, T.; MURAI, I.; NAKAGAWA, S. Long-term melatonin administration reduces hyperinsulinemia and improves the altered fatty-acid compositions in type 2 diabetic rats via the restoration of D-5 desaturase activity. J. Pineal Res., v. 32, p. 2633, 2002.

NISHIDA, S.; SATO, R.; MURAI, I. et al. Effect of pinealectomy on plasma levels of insulin and leptin and on hepatic lipids in type 2 diabetic rats. J. Pineal Res., v. 35, p. 251-256, 2003.

O'BRIEN, I.A.; LEWIN, I.G.; O'HARE, J.P. et al. Abnormal circadian rhythm of melatonin in diabetic autonomic neuropathy. Clin. Endocrinol., v. 24, p. 359-364, 1986.

OBSIL, T.; GHIRLANDO, R.; KLEIN, D.C.; GANGULY, S.; DYDA, F. Crystal structure of the 14-3-3z:serotonin N-acetyltransferase complex: a role for scaffolding in enzyme regulation. Cell, v. 105, p. 257-267, 2001.

PALMER, J.P.; ASPLIN, C.M.; CLEMONS, P., et al. Insulin antibodies in insulin-dependent diabetics before insulin treatment. Science, v. 222, p. 1337-1339, 1983.

PANG, S.F.; TANG, S.; TANG, P.L. Aloxan-induced diabetes and the pineal gland: differential effects on the levels of pineal $\mathrm{N}$-acetylserotonin, pineal melatonin and serum melatonin. J. Pineal Res., v. 2, p. 79-85, 1985. 
PANG, S.F.; DUBOCOVICH, M.L.; BROWN, G.M. Melatonin receptors in peripheral tissues: A new area of melatonin research. Biol. Signals, v.2, p. 177-180, 1993.

PANG, S.F.; LEE, P.P.N.; CHAN, Y.S.; AYRE, E.A. Melatonin secrection and its rhythms in biological fluids. In: YU, H.S.; REITER, R.J. Melatonin - biosynthesis, physiological effects, and clinical applications. Boca Raton: CRC Press. 1993. p. 129-153.

PARFITT, A.; WELLER, J.L.; KLEIN, D.C. Beta adrenergic-blockers decrease adrenergically stimulated $\mathrm{N}$-acetyltransferase activity in pineal glands in organ culture. Neuropharmacology, v. 15, p. 353-358, 1976.

PARK, H.T.; KIM, Y.J.; YOON, S.; KIM, J.B.; KIM, J.J. Distributional characteristics of the mRNA for retinoid $Z$ receptor $\beta$ (RZRß), a putative nuclear melatonin receptor, in the rat brain and spinal cord. Brain Res., v. 747, p. 332-337. 1997.

PAULY, J. E. Chronobiology: anatomy in time. Am. J. Anat., v. 168, p. 365-388, 1983.

PESCHKE, E.; FRESE, T.; CHANKIEWITZ, E.; PESCHKE, D.; PREISS, U.; SCHNEYER, U.; SPESSERT, R.; MÜHLBAUER, E. Diabetic Goto-Kakizaki rats as well as type 2 diabetic patients show a decreased diurnal serum melatonin level and an increased pancreatic melatonin-receptor status. J. Pineal Res., v. 40, p. 135-143, 2006.

PESCHKE, E.; WOLGAST, S.; BAZWINSKY, I.; PÖNICKE, K.; MUHLBAUER, E. Increased melatonin synthesis in pineal glands of rats in streptozotocin induced type 1 diabetes. J. Pineal Res., v. 45, p. 439-448, 2008.

PFEFFER, M.; KÜHN, R.; KRUG, L.; KORF, H-W.; STEHLE, J.H. Rhythmic variation in B1-adrenergic receptor mRNA levels in the rat pineal gland: circadian and developmental regulation. Eur. J. Neurosci., v.10, p. 2896-2904, 1998.

PICINATO, M.C.; HABER, E.P.; CARPINELLI, A.R.; CIPOLLA-NETO, J. Daily rhythm of glucose-induced insulin secretion by isolated islets from intact and pinealectomized rat. $\mathbf{J}$. Pineal Res., p. 172-177, 2002a.

PICINATO, M.C.; HABER, E.P.; CIPOLLA-NETO, J.; CURI, R.; CARVALHO, C.R.O.; CARPINELLI, A.R. Melatonin inhibits insulin secretion and decreases PKA levels without interfering with glucose metabolism in rat pancreatic islets. J. Pineal Res., p. 156-160, 2002b. 
PICINATO, M.C.; HIRATA, A.E.; CIPOLLA-NETO, J.; CURI, R.; CARVALHO, C.R.; ANHÊ, G.F.; CARPINELLI, A.R. Activation of insulin and IGF-1 signaling pathways by melatonin through MT1 receptor in isolated rat pancreatic islets. J. Pineal Res., v. 44, n. 1, p. 88-94, 2008.

PORTHA, B.; BLONDEL, O.; SERRADAS, P.; Mc EVOY, R.; GIROIX, M.H.; KERGOAT, M.; BAILBE, D. The rat models of non-insulin dependent diabetes induced by neonatal streptozotocin. Diabete Metab., v. 15, p. 61-75, 1989.

PROKOPENKO, I.; LANGENBERG, C.; FLOREZ, J.C.; SAXENA, R.; SORANZO, N. et al Variants in MTNR1B influence fasting glucose levels. Nat. Gen., v. 41, n. 1, p. 77- 81, 2009.

PUPO, A. A.; MARREIRO, D. Dosage of insulin levels using radioimmunoassay with double antibodies. AMB Rev. Assoc. Med. Bras., v.16, p.153-156, 1970.

RABIN, D.U.; PLEASIC, S.M.; SHAPIRO, J.A., et al. Islet cell antigen 512 is a diabetesspecific islet autoantigen related to protein tyrosine phosphatases. J. Immunol., v. 152, p. 3183-3188, 1994.

REITER, R.J. The melatonin rhythm: both a clock and a calendar. Experientia, v. 49, p. 654664, 1993.

REITER, R.J. Melatonin: lowering the high price of free radicals. News Physiol. Sci., v. 15, p. 246-250, 2000.

REITER, R.J.; TAN, D.X. What constitutes a physiological concentration of melatonin? J. Pineal Res., v. 34, p. 79-80, 2003.

REITER, R.J.; TAN, D.X.; GITTO, E.; SAINZ, R.M.; MAYO, J.C.; LEON, J.; MANCHESTER, L.C.; VIJAYALAXMI; KILIC, E.; KILIC, U. Pharmacological utility of melatonin in reducing oxidative cellular and molecular damage. Pol. J. Pharmacol., v. 56, n. 2, p. 159-70, 2004.

REPPERT, S.M.; GODSON, C.; MAHLE, C.D.; WEAVER, D.R.; SLAUGENHAUPT, S.A.; GUSELLA, J.F. Molecular characterization of a second melatonin receptor expressed in human retina and brain: The Mel1b melatonin receptor. Proc. Natl. Acad. Sci. USA, v. 92, p. 8734-38, 1995.

REPPERT, S.M.; WEAVER, D.R.; GODSON, C. Melatonin receptors step into the light: cloning and classification of subtypes. Trends Pharmacol. Sci., v. 17, p. 100-102, 1996. 
REYES-TOSO, C.F.; ROSON, M.I.; ALBORNOZ, L.E.; DAMIANO, P.F.; LINARES, L.M.; CARDINALI, D.P. Vascular reactivity in diabetic rats: effect of melatonin. J. Pineal Res., v. 33, p. 81-86, 2002.

RIBELAYGA, C.; PÉVET, P.; SIMMONEAUX, V. Adrenergic and peptidergic regulations of hydroxyindole-O-methyltransferase activity in rat pineal gland. Brain Res., v. 777, p. 247$250,1997$.

RIBELAYGA, C.; GAUER, F.; CALGARI, C.; PEVET, P.; SIMONNEAUX, V. Photoneural regulation of rat pineal hydroxyindole-O-methyltransferase (HIOMT) messenger ribonucleic acid expression: an analysis of its complex relationship with HIOMT activity. Endocrinology, v. 140, p. 1375-84, 1999a.

RIBELAYGA, C.; GARIDOU, M-L.; MALAN, A.; GAUER, F.; CALGARI, C.; PÉVET, P.; SIMONNEAUX, V. Photoperiodic control of the rat pineal AA-NAT and HIOMT gene expression and its effect on melatonin synthesis. J. Biol. Rhythms, v. 14, n. 2, p. 105-115, $1999 b$.

ROBEVA, R.; KIRILOV, G.; TOMOVA, A.; KUMANOV, P. Low testosterone levels and unimpaired melatonin secretion in young males with metabolic syndrome. Andrologia, v. 38 p. 216-220, 2006.

RODRIGUEZ, I. R.; MAZURUK, K.; SCHOEN, T. J.; CHADER, G. J. Structural analysis of the human hydroxyindole-O-methyltransferase gene. J. Biol. Chem., v. 269, p. 31969-31977, 1994.

ROMERO, J.A.; AXELROD, J. Pineal beta-adrenergic receptor: dirunal variation in sensitivity. Science, v. 184, n. 4141, p. 1091-1092, 1974.

ROSEBOOM, P.H.; KLEIN, D.C. Norepinephrine stimulation of pineal cyclic AMP response element-binding protein phosphorylation: primary role of a $\beta$-adrenergic receptor/cyclic AMP mechanism. Mol. Pharmacol., v. 47, p. 439-449, 1995.

ROSEBOOM, P.H.; COON, S.L.; BALER, R.; McCUNE, S.K.; WELLER, J.L.; KLEIN, D.C. Melatonin synthesis: analysis of the more than 150-fold nocturnal increase in serotonin $\mathrm{N}$-acetyltransferase messenger ribonucleic acid in the rat pineal gland. Endocrinology, v. 137, n. 7, p. 3033-3044, 1996.

SAILAJA DEVI, M.M.; SURESH, Y.; DAS, U.N. Preservation of the antioxidant status in chemically-induced diabetes mellitus by melatonin. J. Pineal Res., v. 29, p. 108-115, 2000. 
SAMBROOK, J.; RUSSEL, D. W. Molecular Cloning - A Laboratory Manual. 3. ed. New York: Cold Spring Harbor Laboratory Press, 2001.

SCHAAD, N.C.; VANECEK, J.; RODRIGUEZ, I.R.; KLEIN, D.C.; HOLTZCLAW, L.; RUSSELL, J.T. Vasoactive intestinal peptide elevates pinealocyte intracellular calcium concentrations by enhancing influx: evidence for involvement of a cyclic GMP-dependent mechanism. Mol. Pharmacol., v. 47, p. 923-933, 1995.

SCHMIDT, R.E. Neuronal preservation in the sympathetic ganglia of rats with chronic streptozotocin-induced diabetes. Brain Res., v. 921, p. 256-259, 2001.

SCHNEDL, W.J.; FERBER, S.; JOHNSON, J.H.; NEWGARD, C.B. STZ transport and cytotoxicity: specific enhancement in GUT2-expressing cells. Diabetes, v. 43, p. 1326-1333, 1994.

SEMRA, Y.K.; SMITH, N.C.; LINCOLN, J. Comparative effects of high glucose on different adult sympathetic neurons in culture. Neuroreport, v. 15, p. 2321-2325, 2004.

SERAPHIM, P.M.; BARTOL, I.; CIPOLLA-NETO, J.; MACHADO, U.F. Quantification of GLUT 4 transporters in insulin- sensitive tissues from pinealectomized rats. In: WEBB, S.; PUIG-DOMINGO, M.; MOLLER, M.; PÉVET, P. Pineal Uptade: From Molecular Biology to Clinical Implications. New York: PJD Publications Limited, 1997. p. 99-106.

SHEIN, H.M.; WURTMAN, R.J. Stimulation of $\left[{ }^{14} \mathrm{C}\right]$ tryptophan 5-hydroxylation by norepinephrine and dibutyryl adenosine 3,5' monophosphate in rat pineal organ cultures. Life Sci., v. 10, p. 935-940, 1971.

SHIBUYA, H.; TORU, M.; WATANABE, S. A circadian rhythm of tryptophan hydroxylase in rat pineals. Brain Res., v. 138, p. 364-368, 1978.

SIMMONEAUX, V.; RODEAU, J.-L.; CALGARI, C.; PÉVET, P. Neuropeptide Y increases intracellular calcium in rat pinealocytes. Eur. J. Neurosci., v. 11, p. 725-728, 1999.

SIMONNEAUX, V.; RIBELAYGA, C. Generation of the melatonin endocrine message in mammals: a review of the complex regulation of melatonin synthesis by norepinephrine, peptides, and other pineal transmitters. Pharmacol. Rev., v. 55, p. 325-395, 2003.

SINDELAR, D.K.; HAVEL, P.J.; SEELEY, R.J.; WILKINSON, C.W.; WOODS, S.C.; SCHWARTZ, M.W. Low Plasma Leptin Levels Contribute to Diabetic Hyperphagia in Rats. Diabetes, v. 48, p. 1275-1280, 1999. 
SITARAM, B.R.; LEES, G.J. Diurnal rhythm and turnover of tryptophan hydroxylase in the pineal gland of the rat. J. Neurochem., v. 31, p. 1021-1026, 1978.

SITARAM, B.R.; LEES, G.J. Effect of oxygen on the induction of tryptophan hydroxylase by adrenergic agents in organ cultures of rat pineal glands. J. Neurochem., v. 42, p. 1183-1185, 1984.

SIVITZ, W.I.; WALSH, S.; MORGAN, D.; DONOHOUE, P.; HAYNES, W.; LEIBEL, R.L. Plasma Leptin in Diabetic and Insulin-Treated Diabetic and Normal Rats. Metabolism, v. 47, n. 5, p. 584-591, 1998.

SKORUPA, A.L.; GARIDOU, M.-L.; BOTHOREL, B.; SABOUREAU, M.; PÉVET, P. ; CIPOLLA-NETO, J.; SIMONNEAUX, V. Pineal melatonin synthesis and release are not altered throughout the estrous cycle in female rats. J. Pineal Res., v. 34, p. 53-59, 2003.

SPESSER, T.R.; RAPP, M.; JASTROW, H.; KARABUL, N.; BLUM, F.; VOLLRATH, L. A differential role of CREB phosphorylation in cAMP-inducible gene expression in the rat pineal. Brain Res., v. 864, p. 270-280, 2000.

STEBELOVÁ, K.; HERICHOVÁ, I.; ZEMAN, M. Diabetes induces changes in melatonin concentrations in peripheral tissues of rat. Neuro Endocrinol. Lett., v. 28, n. 2, p. 159-65, 2007.

SUGDEN, D.; VANECEK, J.; KLEIN, D.C.; THOMAS, T.P.; ANDERSON, W.B. Activation of protein kinase $\mathrm{C}$ potentiates isoprenaline-induced cyclic AMP accumulation in rat pinealocytes. Nature, v. 314, p. 359-361, 1985.

SUGDEN, A.L.; SUGDEN, D.; KLEIN, D.C. Essential role of calcium influx in the adrenergic regulation of cAMP and cGMP in rat pinealocytes. J. Biol. Chem., v. 261, p. 11608-11612, 1986.

SUGDEN, A.L.; SUGDEN, D.; KLEIN, D.C. $\alpha_{1}$-Adrenoceptor activation elevates cytosolic calcium in rat pinealocytes by increasing net influx. J. Biol. Chem., v. 262, p. 741-745, 1987.

SUGDEN, D. Melatonin biosynthesis in the mammalian pineal gland. Experientia, v. 45, p. 922-931, 1989.

SUGDEN, D. Comparison of circadian expression of tryptophan hydroxylase isoform mRNAs in the rat pineal gland using real-time PCR. J. Neurochem., v. 86, p. 1308-1311, 2003. 
TAMOTSU, S.; SCHOMERUS, C.; STEHLE, J.H.; ROSEBOOM, P.H.; KORF, H.W. Norepinephrine-induced phosphorylation of the transcription factor CREB in isolated rat pinealocytes: an immunocytochemical study. Cell Tissue Res., v. 282, p. 219-26, 1995.

TANKOVA, T.; KOEV, D.; DAKOVSKA, L.; KIRILIV, G. The effect of replaglinide on insulin secretion and oxidative stress in type 2 diabetic patients. Diabetes Res. Clin. Pract., v. 59, p. 43-49, 2003.

TATTERSALL, R.B.; PYKE, D.A. Diabetes in identical twins. Lancet, v. 28, p.1120-1125, 1972.

TAZAVARA, E.T.; POUILLE, Y.; DEFER, N.; HANOUNE, J. Diurnal variation of the adenylyl cyclase type 1 in the rat pineal gland. Proc. Natl. Acad. Sci., v. 93, p. 11208-11212, 1996.

THREATTE, G.A.; HENRY, J.B. Carboidratos. In: HENRY, J.B. (Ed.). Diagnósticos Clínicos e Tratamento por Métodos Laboratoriais. São Paulo: Editora Manole, 1999. p. 194-207.

TODD, J.A.; BELL, J.I.; McDEVIN, H.O. HLA-DQb gene contributes to susceptibility and resistance to insulin-dependent diabetes mellitus. Nature, v. 329, p. 599-604, 1987.

TORQUATO, M.T.C.G. et al. Prevalence of diabetes mellitus and impaired glucose tolerance in the urban population aged 30-69 years in Ribeirão Preto (São Paulo), Brazil. Sao Paulo Med. J., v. 121, n. 6, p. 224-230, 2003.

TORMO, M.A.; ROMERO de TEJADA, A.; MORALES, I.; PAREDES, S.; SANCHEZ, S.; BARRIGA, C.; HERNÁNDEZ, R. Orally administered tryptophan and experimental type 2 diabetes. Mol. Cell. Biochem., v. 261, p. 57-61, 2004.

TRULSON, M.E.; JACOBY, J.H.; MACKENZIE, R.G. Streptozotocin-induced diabetes reduces brain serotonin synthesis in rats. J. Neurochem., v. 46, n. 4, p. 1068-72, 1986.

TSAI, M-H.; WEI, I-H.; JIANG-SHIEH, Y-F.; JOU, M-J.; KO, M-H.; CHEN, H-M.; WU, C$\mathrm{H}$. Expression of protein gene product 9.5, tyrosine hydroxylase and serotonin in the pineal gland of rats with streptozotocin-induced diabetes. Neurosci. Res., v. 60, p. 233-243, 2008.

TSUBONE, T.; MASAKI, T.; KATSURAGI, I.; TANAKA, K.; KAKUMA, T.; YOSHIMATSU, H. Leptin downregulates ghrelin levels in streptozotocin-induced diabetic mice. Am. J. Physiol. Reg. Integr. Comp. Physiol., v. 289, p. 1703-1706, 2005. 
TUTUNCU, N.B.; BATUR, M.K.; YILDIRIR, A.; TUTUNCU, T.; DEGER, A.; KORAY, Z.; ERBAS, B.; KABAKCI, G.; AKSOYEK, S.; ERBAS, T. Melatonin levels decrease in type 2 diabetic patients with cardiac autonomic neuropathy. J. Pineal Res., v. 39, n. 1, p. 43$9,2005$.

VANECEK, J.; SUGDEN, D.; WELLER, J. L.; KLEIN, D. C. Atypical synergistic $\alpha 1$ - and Badrenergic regulation of adenosine 3',5'-monophosphate and guanosine 3',5'-monophosphate in rat pinealocytes. Endocrinology, v.116, p. 2167-2173, 1985.

VOLLRATH, L. The pineal organ. In: OKSCHE, A.; VOLLRATH, L. Handbuch Der Mikroskopischen Anatomie Des Menschen, v. 6/7. Berlin: Springer, 1981.

VURAL, H.; SABUNCU, T.; ARSLAN, S.O.; AKSOY, N. Melatonin inhibits lipid peroxidation and stimulates the antioxidant status of diabetic rats. J. Pineal Res., v. 31, n. 3, p. 193-198, 2001.

WAJCHENBERG, B.L. Tratado de Endocrinologia Clínica. São Paulo: Ed. Roca, 1992.

WEBLEY, G.E.; MEHL, H.; WILLEY, K.P. Validation of a sensitive direct assay for melatonin for investigation of circadian rhythms in different species. J. Endocrinol., v. 106, p. 387-394, 1985.

WEST, E.; SIMON, O.R.; MORRISON, E.Y. Streptozotocin alters pancreatic beta-cell responsiveness to glucose within six hours of injection into rats. West Indian Med. J., v. 45, p. 60-62, 1996.

WILSON, J.D; FOSTER, D.W. Tratado de Endocrinologia. 7. ed. São Paulo: Manole, 1988. p. 667-9, 674-9.

WINIARSKA, K.; FRACZYK, T.; MALINSKA, D.; DROZAK, J.; BRYLA, J. Melatonin attenuates diabetes-induced oxidative stress in rabbits. J. Pineal Res., v. 40, n. 2, p. 168-176, 2006 .

WORLD HEALTH ORGANIZATION, INTERNATIONAL DIABETES FEDERATION. Definition and diagnosis of diabetes mellitus and intermediate hyperglycemia: report of a WHO/IDF consultation. Geneva: WHO Press, 2006. 52 p.

YAGA, K.; REITER, R.J.; RICHARDSON, B.A. Tryptophan loading increases daytime serum melatonin levels in intact and pinealectomized rats. Life Sci., v. 52, n. 14, p. 12311238, 1993. 
YAVUZ, O.; CAM, M.; BUKAN, N.; GUVEN, A.; SILAN, F. Protective effect of melatonin on beta-cell damage in streptozotocin-induced diabetes in rats. Acta Histochem., v. 105, n. 3, p. 261-266, 2003.

YOUNG, S.N.; ANDERSON, G.M. Factors influencing melatonin, 5-hydroxytryptophol, 5hydroxyindolacetic acid, 5-hydroxytryptamine and tryptophan in rat pineal glands. Neuroendocrinology, v. 35, p. 464-468, 1982.

YOUNG, M. E.; WILSON, C. R.; RAZEGHI, P.; GUTHRIE, P. H.; TAEGTMEYER, H. Alterations of the circadian clock in the heart by streptozotocin-induced diabetes. J. Mol. Cell. Cardiol., v. 34, p. 223-231, 2002.

YU, H.S.; TSIN, A.T.C.; REITER, R.J. Melatonin: history, biosynthesis and assay methodology. In: YU, H.S.; REITER, R. Melatonin - biosynthesis, physiological effects, and clinical applications. Boca Raton: CRC Press, 1993. p. 1-16.

ZANQUETTA, M.M.; SERAPHIM, P.M.; SUMIDA, D.H.; CIPOLLA-NETO, J.; MACHADO, U.F. Calorie restriction reduces pinealectomy-induced insulin resistance by improving GLUT4 gene expression and its translocation to the plasma membrane. J. Pineal Res., v. 35, n. 3, p. 141-148, 2003.

ZIMMERMANN, R.C.; MCDOUGLE, C.J.; SCHUMACHER, M.; OLCESE, J.; MASON, J.W.; HENINGER, G.R.; PRICE, L.H. Effects of acute tryptophan depletion on nocturnal melatonin secretion in humans. J. Clin. Endocrinol. Metab., v. 75, n. 5, p. 1160-1164, 1993.

ZIMMET, P.; ALBERTI, K.G.; SHAW, J. Global and social implications of the diabetes epidemic. Nature, v. 414, p. 782-787, 2001. 